\title{
Using Process Stories to Foster Process Flexibility: The Experts' Viewpoint
}

\author{
Nguyen Hoang Thuan \\ RMIT University, Viet Nam \\ Thuan.NguyenHoang@rmit.edu.vn
}

\section{Hoang Ai-Phuong}

RMIT University, Viet Nam

\author{
Mathews Nkhoma \\ RMIT University, Viet Nam
}

\section{Pedro Antunes}

LASIGE, Faculdade de Ciências, Universidade de Lisboa/University of Lisbon, Portugal

\section{Abstract}

Process flexibility is essential for organizations coping with uncertainty, emergence, and change. In this study, we research how process stories may lessen friction in realizing flexible processes. We use friction as a metaphor, which characterizes the realization of flexible processes as handling two opposing forces: one pushes towards flexibility while the other pulls against flexibility. Using in-depth interviews with BPM experts as a data-gathering technique, we provide insights into the dynamics of friction in the BPM lifecycle. We also provide empirical evidence about the capability of process stories to lessen friction in realizing flexible processes. This research contributes to understand the context where process stories may be most fit to realize process flexibility and adds knowledge about practical complaints experienced by BPM experts when realizing process flexibility.

Keywords: Business Processes, Process Flexibility, Process Stories, Empirical Study, Qualitative Interviews.

\section{Introduction}

Process flexibility enables organizations to cope with uncertainty, emergence, and change. Many organizations nowadays face uncertain business environments (Cognini, Corradini, Gnesi, Polini, \& Re, 2018; Mejri, Ghannouchi, \& Martinho, 2016), including a constant state of emergence (de Albuquerque \& Christ, 2015), and operational vagaries (Antunes, Tate, \& Pino, 2019; Haseeb, Ahmad, Malik, \& Anjum, 2019). These 'push' towards the realization of more flexible processes. Besides, organizations also face significant 'pull' against process flexibility from both humans and software technology. For instance, enterprise systems, with their traditional emphasis on structure and control, can generate significant pull against process flexibility (Qu, Ding, Shou, Zhou, \& Du, 2014; Rettig, 2007). Employees and middle managers can also exhibit more or less intense resisting behaviours to change initiatives (Bareil, 2013).

We borrow from physics the notion of friction to highlight the forces that emerge when we try to push an object against a surface. Similarly, when organizations try to push a new flexible process, they must handle the resisting pull against it. Understanding and resolving this type of friction is a concern of Business Process Management (BPM). After all, BPM is fundamentally concerned with managing the relationships between humans, business 
processes, and software technology to help organizations achieve performance improvements (Dumas, La Rosa, Mendling, \& Reijers, 2018; Rosemann \& Recker, 2006).

It is important for BPM experts to understand and deal with friction in realizing flexible processes. Friction highlights a longstanding tension between standardization and flexibility in organizations (Boudreau \& Robey, 1996; de Albuquerque \& Christ, 2015; Feldman \& Pentland, 2003), which is also apparent in BPM. On the one hand, organizations are usually structured around standardized procedures and behaviours (Davenport, 2005; Romero, Dijkman, Grefen, \& van Weele, 2015), which pull against process flexibility. On the other hand, organizations also have to deal with business uncertainties, environmental changes, conflicting viewpoints, unique cases, variations, innovations, and evolutionary changes (Cognini et al., 2018; Mejri et al., 2016; Thuan, Phuong, George, Nkhoma, \& Antunes, 2020), which push towards process flexibility. Without understanding the different forces involved in friction, BPM experts may find it difficult to realize flexible processes.

In this study, we propose process stories to help BPM experts understand the dynamics of friction in realizing process flexibility. Process stories rely on storytelling theory to communicate a variety of viewpoints over a business process (Antunes, Pino, Tate, \& Barros, 2020; Haggège \& Vernay, 2019; Hayes, Lee, \& Dourish, 2011). Process stories have been used to analyse organizational business processes and the related views over these processes (Antunes et al., 2020; Leite, Antunes, Guimarães, \& Pino, 2019; Simões, Antunes, \& Carriço, 2018). We suggest that the capacity of conveying diverse viewpoints about a process can help BPM experts to understand and deal with the various forces involved in the dynamics of friction. Consequently, the study addresses the following research question: How can BPM experts use process stories to reduce friction in realizing process flexibility?

To answer this question, this study follows a tradition of exploratory studies and adopts a qualitative approach (Saldaña, 2015). In particular, the study relies on in-depth interviews with BPM experts. We gather the participants' views over the dynamics of friction in processes they have responsibility for; and gather the participants' judgements about the adoption of process stories to support the realization of flexible processes. As a result, the interviews enable us to understand the dynamics of friction in flexible processes and the experts' perceptions about the adoption of process stories to support process flexibility.

This study contributes to research in the BPM field with a dynamic understanding of the realization of process flexibility, which uses friction as a metaphor. It provides insights about the elements pushing towards and pulling against process flexibility in the BPM lifecycle. The study further provides insights into the strengths and weaknesses of process stories as a method supporting the realization of flexible processes. The empirical evidence complements other theoretical efforts promoting the adoption of storytelling in business modelling (Antunes et al., 2019; Haggège \& Vernay, 2019; Hayes et al., 2011). From a more practical perspective, this study provides guidance on how practitioners can use process stories to reduce existing friction when realizing process flexibility.

The remainder of this paper is structured as follows: Section 2 sets up the background of the research. Section 3 develops and justifies our research framework. Section 4 describes the adopted research method. The interview results are presented in Section 5. Section 6 discusses the implications of this research for the BPM field. Finally, Section 7 provides some concluding remarks and suggests future research directions. 


\section{Background}

\subsection{Prior research on process modelling standardization versus flexibility}

Research in the BPM field has resulted in a plethora of theories, methods and tools that assist organizations in managing business processes (Recker \& Mendling, 2016). A traditional and highly relevant research stream in the field concerns formal modelling of business processes. This stream addresses standardized formalisms that capture BPM-related phenomena (Recker \& Mendling, 2016) and support modelling the different ways in which a process can be handled (van der Aalst, 2013). Process standardization is considered essential for functional analysis and optimization of organizations (Davenport, 2005; Romero et al., 2015; Schäfermeyer, Rosenkranz, \& Holten, 2012). It allows the organization to specify transparent processes, shorten processing time, and harmonize process activities (Münstermann, Eckhardt, \& Weitzel, 2010; Romero et al., 2015; Tregear, 2015). In addition, formal enough process models are essential for technology support to business processes using process-aware information systems (van der Aalst, 2013).

While the above literature has realized the benefits of standardized processes, another stream of literature has highlighted the needs for flexible processes. In particular, uncertain business environments (Mejri et al., 2016), emergent situations (de Albuquerque \& Christ, 2015), and operational vagaries (Antunes et al., 2019; Haseeb et al., 2019) are valid grounds for conferring some variability and flexibility on business processes. Further, other factors such as new working methods, exceptions, and technology evolution also call for flexible business processes (Cognini et al., 2018; Simões, Thuan, Jonnavithula, \& Antunes, 2015).

Considering these two streams of literature, researchers have for long pointed out several competing factors related to process modelling, which complicate the realization of process flexibility (de Albuquerque \& Christ, 2015; Reichert \& Weber, 2012; Zelt, Recker, Schmiedel, \& vom Brocke, 2019). We now review these competing factors in relation to process flexibility, including design versus use, structured versus unstructured processes, complexity versus simplicity, control versus value, technical versus social focus.

Design versus use. BPM practices traditionally involve a design-use cycle, where a process is designed and modelled, and then the model is used by a process-aware information system to enact the process. This cycle impacts flexibility, as process changes require organizations to continuously go through design-use cycles, which have inherent costs and complications (Reichert, 2018). A variety of approaches have been proposed to support runtime dynamic changes and thus avoid going through the design-use cycle (Krumeich, Weis, Werth, \& Loos, 2014; Reichert \& Weber, 2012; Rosa, van der Aalst, Dumas, \& Milani, 2017). However, these approaches may introduce mismatches between what has been modelled and what is executed. Reichert (2018) suggests that the only feasible way to cope with this problem is to eliminate the design-use dichotomy, allowing processes to be dynamically (re)designed based on use.

Structured versus unstructured. Van Der Aalst et al. (2009, p. 99) point out that "processaware information systems tend to either support business processes or provide flexibility" but not both. This happens because process-aware information systems require processes to be structured, due to execution constraints. On the other hand, flexibility requires processes to be less structured to accommodate changes. The problem is further complicated because traditional BPM tends to structure processes around activities, which commit organizations to 
respond with certain activities to specific events. A variety of solutions have been proposed to increase the capacity to deal with changes in a structured way (Hidri, M'tir, Saoud, \& GhediraGuegan, 2019; Reichert \& Weber, 2012). Examples include adding exceptions and deviations to process models (Hallerbach, Bauer, \& Reichert, 2010; Marcinkowski \& Gawin, 2019). However, these approaches increase modelling complexity and do not accommodate true exceptions and emergence.

Complexity versus simplicity. It is undeniable that process-aware information systems can expedite the enactment of business processes from model designs (Dumas et al., 2018; van der Aalst, 2013). A variety of software platforms support a rapid roundtrip between modelling and enactment using BPMN, such as ARIS, Camunda, Signavio, and Oracle BPM Suite. This would suggest a "triumphant vision many buy into," that "software is fully integrated and intelligently controls infinitely complex business processes while remaining flexible enough to adapt to changing business needs" (Rettig, 2007, p. 1). However, the results may not be as expected. Svejvig and Jensen (2013, p. 14) highlight the conflict between "match the current business processes" versus "match the standard package". Also in the studied case, the organization failed its first implementation attempt due to complex institutional practices that could not be modelled properly. The second attempt was successful as the organization decided to conform to a predefined process provided by software platform vendors to reduce complexity. It thus seems that expediting complex process enactment compromises process flexibility.

Control versus value. Vom Brocke et al. (2010) point out other factors in play, where the main focus of process modelling is often more related to control a set of activities (required to enact the process) than to design a process that brings actual value to the organization. As such, current process modelling practices focus more on aspects that bring low impact to the organization instead of being value-oriented. Proposals to address this problem suggest extending process modelling beyond control to focus on value drivers and needs (e.g., financial and customer satisfaction). However, moving beyond control can make it more difficult to enact business processes in process-aware information systems, especially because value drivers and needs are more elusive and reflect conflicting views about what must be done.

Technical versus social. When modelling business processes, BPM experts tend to focus on the technical aspects of the process, e.g., defining required resources or alternative paths in response to a certain event. However, processes must be enacted in ways that are "locally and institutionally acceptable" (Hayes et al., 2011). Therefore, the enactment of a more or less flexible process depends on the characteristics of the individuals and organizations involved in the process (Afflerbach, Kastner, Krause, \& Röglinger, 2014; de Albuquerque \& Christ, 2015). As noted by de Albuquerque and Christ (2015), process models should be regarded as socio-technical artefacts, which must combine both technical and social properties. The consideration for social practice requires BPM experts to take full account of the 'social world' in which processes take place, considering the nuances and mutual compromises found in the relationships between the technical and the social.

Considering all these factors, we suggest that there is no one-size-fit-all modelling solution for realizing flexible processes. Rather, BPM experts must identify and deal with the different factors and their conflicts, which form two opposing forces, namely push and pull. The push 
force moves forward process flexibility, while the pull one resists process flexibility. In the next section, we link these forces to the BPM lifecycle.

\subsection{Process flexibility and the BPM lifecycle}

The typical BPM lifecycle encompasses different stages: process analysis, design/modelling, enactment/execution, and monitoring/improvement (Cognini et al., 2018). As such, the realization of flexible processes must be tackled in all these stages. It ranges from analysing how the organization responds (or not) to internal and external demands for flexibility, resolving issues with the interactions between humans and software applications, servicing the organization and its clients with appropriate software, and finally monitoring and improving flexible processes according to specific goals and targets (Aysolmaz, Schunselaar, Reijers, \& Yaldiz, 2019; Hallerbach, Bauer, \& Reichert, 2008; Reichert, Hallerbach, \& Bauer, 2015).

In all these stages, friction when realizing flexible processes can be increased (or reduced) due to internal and external factors. For instance, difficulties in analysing what drives process flexibility create friction; difficulties in modelling operational changes also create friction; and problems in executing and monitoring process variations contribute to friction as well. Cognini et al. (2018)'s review identifies other difficulties and problems that contribute to increasing (or decreasing) friction when realizing process flexibility in each and all stages.

Even though the realization of process flexibility involves the entire BPM lifecycle, research in the BPM field has been mainly focused on the enactment/execution stage (Cognini et al., 2018). Researchers have been developing software approaches that support dynamic, case-based, and ad hoc changes in processes during run-time (Braun, Schlieter, Burwitz, \& Esswein, 2016; Hallerbach et al., 2010; Sid, Reichert, \& Ghomari, 2019). For instance, the Provop approach allows users to automatically adjust their workflows to small variations over a baseline process, which is accomplished by reconfiguring the sequence of activities (Hallerbach et al., 2010). Relying on our friction metaphor, these approaches can be characterized as 'pull' solutions, whereby software systems reconfigure flexible processes in runtime. Hence, they lessen the pull of software technology and people against process flexibility.

However, to further reduce friction, researchers should also examine the push towards the realization of more flexible processes. We stress here the etymology of the word 'push,' which refers to proactivity in exerting a force towards an intended goal. This proactive 'push' empowers organizations to imagine and explore alternative and emergent scenarios without being overly constrained by standardization and red tape (Boudreau \& Robey, 1996; de Albuquerque \& Christ, 2015; Feldman \& Pentland, 2003).

It is worthwhile to note that pushing towards the realization of more flexible processes requires adequate process analysis and articulation with the later stages of the BPM lifecycle. Such articulation is not only necessary because analysis is a logical antecedent for the other stages (Haseeb et al., 2019), but also because process analysis is not done in a vacuum. The main goal of BPM is to help organizations achieve performance improvements, which requires articulation of all stages. Knowledge about a flexible process is attained in the analysis stage. This knowledge helps to generate a representation of the flexible process in the design/modelling stage, which is then used by software technology (Cognini et al., 2018; van der Aalst, Ter Hofstede, \& Weske, 2003). Furthermore, an examination of the analysis and 
design/modelling stages regarding process flexibility also contributes to the identifications of barriers and limitations in current software technology (Hayes et al., 2011).

In summary, while the BPM field has recognised both the push and the pull on process flexibility, existing efforts mainly focus on reducing the pull against process flexibility in the enactment/execution stage (Cognini et al., 2018). Few efforts have examined how to push towards more flexible processes (Antunes et al., 2019; Bauer, 2019), and even fewer efforts have investigated the two forces together. This gap prevents us from understanding the nature of the two opposing forces, which affects our full realization of process flexibility. This study fulfils the gap by exploring if process stories can support BPM experts in dealing with the dynamics of friction when realizing process flexibility.

\subsection{Process stories as a method pushing towards more flexible processes}

From the above discussion, the emerging concern is how to push towards process flexibility from process analysis to the other stages of the BPM lifecycle. Process stories have been proposed as a method that helps to communicate and understand the contextual aspects of human participation in business processes (Antunes et al., 2020; Antunes et al., 2019). Process stories rely on storytelling theory to narrate what happens in a business process using a combination of textual and visual elements. Each story narrates the business process from a unique viewpoint, which could be anyone with an interest in the process (process owners, participants, external actors, BPM experts, etc.). The identification and elicitation of process stories may support BPM experts in pushing towards more flexible processes, as process stories highlight a variety of goals and patterns of action (Haggège \& Vernay, 2019). Process stories allow the process to adapt and evolve without much impact on process design and modelling, as new stories can be brought into the collection.

A few research studies have explored process stories as a method to analyse business processes, assessing the capacity of process stories to examine business scenarios and capture process knowledge (Antunes et al., 2020; Haggège \& Vernay, 2019). Some works have specifically used process stories as an instrument to analyse process flexibility and contextualisation, focusing on the method's strengths to highlight variant scenarios lived by different people participating in the process (Antunes et al., 2019; Simões et al., 2018). To some extent, these studies indicate that process stories are promising to push the realization of process flexibility. As such, this study assesses if process stories can help BPM experts to reduce friction and push towards more flexible processes in the BPM lifecycle.

\section{Conceptual Framework of Research}

In qualitative studies, an established tradition is structuring the research using conceptual frameworks (Miles, Huberman, \& Saldaña, 2014; Saldaña, 2015). Conceptual frameworks help to define the perimeter of the research, guide data gathering and analysis through providing anticipatory data reduction and provide a frame of reference for identifying research contributions (Miles et al., 2014). In the present study, the proposed framework identifies the main constructs involved in the realization of process flexibility, supports data collection in the interviews, and serves to synthesise the research contributions. 


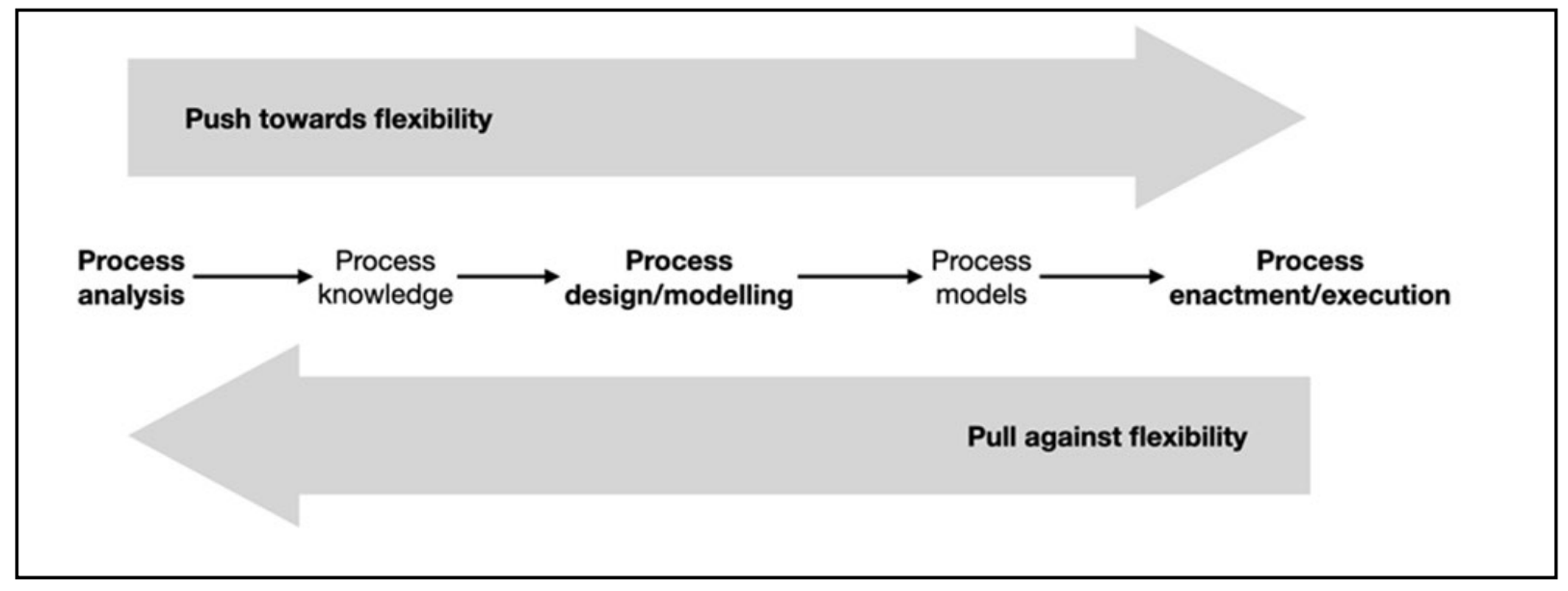

Figure 1. Friction in the realization of process flexibility, which is characterized as the push towards flexibility and pull against flexibility across the stages of the BPM lifecycle

The proposed framework (Figure 1) is grounded on the BPM lifecycle, which covers a set of BPM undertakings that cut across almost every process realization (Bernardo, Galina, \& de Pádua, 2017; de Morais, Kazan, de Pádua, \& Costa, 2014). We consider three stages of the BPM lifecycle: analysis, design/modelling, and enactment/execution (we note that to decrease the extent and complexity of our research, we do not consider process monitoring/improvement).

In the related literature, we further identify two relevant mediators in the BPM lifecycle: process knowledge and process models. Process knowledge is the output of the analysis stage, which identifies relevant business processes and associated activities. Process knowledge is essential to design and model business processes (Dumas et al., 2018). Process models are the output of the design/modelling stage; they represent the identified processes using a particular modelling language (Andaloussi, Burattin, Slaats, Kindler, \& Weber, 2020). Process models are also essential to enact and execute business processes using process-aware information systems.

Given the three stages and two mediators, our conceptual framework characterizes the notion of friction in relation to the realization of process flexibility. The framework highlights that friction involves multiple stages of the BPM lifecycle (we recall section 2.2 for details), where our focus is on the three early stages. Further, friction is caused by two opposing forces: push towards flexibility and pull against flexibility. These pushing and pulling forces may be generated at any stage of the BPM lifecycle and are expected to spill over the other stages. After all, the three stages are significantly interdependent (Haseeb et al., 2019).

We note this framework remains open to new elements emerging from the interviews. With this openness in mind, we used the framework to structure conversations with the interviewees.

\section{Research Method}

We adopted qualitative interviews with domain experts to explore whether process stories could contribute to reducing friction in realizing flexible processes. Interviews enable participants to reflect on their experiences across a range of cases and scenarios for understanding process flexibility, which can complement other particular case studies (de Albuquerque \& Christ, 2015; Haggège \& Vernay, 2019; Simchi-Levi, Wang, \& Wei, 2018). 
Further, interviews provide a formative and (quasi)naturalistic way to evaluate method artifacts like process stories within real organizational contexts (Venable, Pries-Heje, \& Baskerville, 2016). Finally, interviews are considered appropriate to generate rich data, as BPM experts can discuss both their business process and the related contexts (Gross et al., 2021; Javidroozi, Shah, \& Feldman, 2019). Next, we discuss the adopted procedure, which covers the recruitment of participants, data collection, data analysis, and validity checks.

The participants were recruited by emails, public websites, and professional networks. All participants are experienced business and process managers. While having different roles in their companies, all participants regard themselves as BPM experts and have dealt with process flexibility issues in their companies. Eleven subjects voluntarily participated in the interviews. This sample size is appropriate for three reasons. First, it helps us to achieve data saturation, as the new interview data tended to repeat the collected data (Saunders et al., 2018). While data saturation was reached after nine interviews, we conducted two additional interviews to confirm data saturation. Second, although this sample size may limit the generalization of findings, it enables us to analyse the topic in greater details and compare the participants' responses on the topic, as suggested by Fischer et al. (2020). Finally, our sample size aligns with Creswell's (2009) suggestion regarding qualitative sampling (between 5 and 25 participants).

All interviews lasted about 30-45 minutes and were conducted between 2020 and 2021. They were audio-recorded and transcribed by a research assistant. The transcripts consisted of an average of 4348 words (or approximately 10 pages). Table 1 summarises the sample's demographic information.

\begin{tabular}{|c|c|c|c|c|c|}
\hline $\begin{array}{l}\text { Expert } \\
\text { ID }\end{array}$ & Roles & $\begin{array}{c}\text { Years of } \\
\text { experience }\end{array}$ & Business sectors & Gender & $\begin{array}{c}\text { Business processes } \\
\text { under their } \\
\text { responsibility } \\
\end{array}$ \\
\hline $\mathrm{A}$ & $\begin{array}{l}\text { Business owner and } \\
\text { manager }\end{array}$ & $>20$ & Lottery wholesaler & Female & Lottery distribution \\
\hline B & $\begin{array}{l}\text { Head of multimedia } \\
\text { department }\end{array}$ & $10-20$ & $\begin{array}{l}\text { Newspaper } \\
\text { publisher }\end{array}$ & Male & Publishing articles \\
\hline $\mathrm{C}$ & Business coordinator & $10-20$ & $\begin{array}{l}\text { Newspaper } \\
\text { publisher }\end{array}$ & Female & Publishing articles \\
\hline $\mathrm{D}$ & $\begin{array}{l}\text { Business process } \\
\text { manager }\end{array}$ & $1-10$ & E-commerce & Male & $\begin{array}{l}\text { Product returns and } \\
\text { refunds }\end{array}$ \\
\hline $\mathrm{E}$ & $\begin{array}{l}\text { Business process } \\
\text { manager }\end{array}$ & $1-10$ & E-commerce & Male & $\begin{array}{l}\text { Product returns and } \\
\text { refunds }\end{array}$ \\
\hline $\mathrm{F}$ & Team leader & $1-10$ & Higher Education & Female & $\begin{array}{l}\text { English-level class } \\
\text { arrangement }\end{array}$ \\
\hline G & Manager & $1-10$ & Consulting agency & Male & $\begin{array}{l}\text { Consulting process to } \\
\text { open new business entity }\end{array}$ \\
\hline $\mathrm{H}$ & $\begin{array}{l}\text { Business owner and } \\
\text { manager }\end{array}$ & $1-10$ & $\begin{array}{l}\text { Home appliance } \\
\text { retailer }\end{array}$ & Female & Product sales \\
\hline $\mathrm{I}$ & Manager & $>20$ & Market research & Male & Market research \\
\hline $\mathrm{J}$ & Operations Director & $1-10$ & Market research & Male & Market research \\
\hline K & Business Director & $1-10$ & $\begin{array}{l}\text { Furniture } \\
\text { manufacturer }\end{array}$ & Male & $\begin{array}{l}\text { Requirements gathering } \\
\text { and furniture } \\
\text { implementation }\end{array}$ \\
\hline
\end{tabular}

Table 1. Experts' profile ( $N=11)$ 
Data collection was conducted through in-depth interviews and using semi-structured questions to guide the conversations. The questions (see Appendix A) were organized into three main categories: 1) background questions asking about the participant's experience with $\mathrm{BPM}$; 2) questions exploring issues related to process flexibility in selected business processes (see below); and 3) questions exploring the adoption of process stories in the realization of process flexibility.

Before the interviews, the participants were asked to identify a specific business process under their responsibility, which would be the focus of discussion during the interviews. With the participant's prior approval, the selected processes were modelled in BPMN and represented using process stories (Appendix B shows an example of a business process represented using the two methods). During the interviews, we presented both the BPMN models and process stories to the participants, who were then asked to discuss the two methods with regards to the realization of flexible processes in their own context.

\begin{tabular}{|c|c|c|c|}
\hline \multicolumn{2}{|c|}{ Structural coding } & \multicolumn{2}{|r|}{ Thematic coding } \\
\hline $\begin{array}{c}\text { Structural } \\
\text { dimensions }\end{array}$ & Structural codes & Codes & Example data \\
\hline \multirow{4}{*}{$\begin{array}{l}\text { Friction in } \\
\text { realizing } \\
\text { process } \\
\text { flexibility }\end{array}$} & \multirow{3}{*}{$\begin{array}{l}\text { Push towards } \\
\text { flexibility }\end{array}$} & $\begin{array}{l}\text { Demands for } \\
\text { uncertainty, emergence, } \\
\text { change, exceptions, and } \\
\text { variations }\end{array}$ & $\begin{array}{l}\text { - Due to the characteristic of this business, there're } \\
\text { so many exceptions } \\
\text { - When we operate the business process, there's } \\
\text { always an exception. There are always things that } \\
\text { the client asks out of the box } \\
\text { - So, we need to act fast in building that real time } \\
\text { processes which will have } 80 \% \text { standardization } \\
\text { because we need to have } 20 \% \text { flexibility right at the } \\
\text { end of the day, we cannot have } 100 \% \text { straight line. } \\
\text { That doesn't work in any market. }\end{array}$ \\
\hline & & $\begin{array}{l}\text { Standard processes do } \\
\text { not capture exceptions, } \\
\text { looseness, variations, } \\
\text { adaptations, and } \\
\text { evolutions }\end{array}$ & $\begin{array}{l}\text { - Obviously, it is a standard process showing each } \\
\text { step of what we need to do, and the exceptions } \\
\text { have not been shown here } \\
\text { - So, this thing is just a standard and common } \\
\text { process, and if you ask about exceptions, there are so } \\
\text { many of them that I cannot tell you all }\end{array}$ \\
\hline & & $\begin{array}{l}\text { Fostering new solutions } \\
\text { in the process }\end{array}$ & $\begin{array}{l}\text { - After reading this, we have to find a solution to solve } \\
\text { it } \\
\text { - BPM experts can redraw a whole new process }\end{array}$ \\
\hline & $\begin{array}{l}\text { Pull against } \\
\text { flexibility }\end{array}$ & $\begin{array}{l}\text { Demands for } \\
\text { abstraction, standards, } \\
\text { structure, and control } \\
\text { rules }\end{array}$ & $\begin{array}{l}\text { - The standard workflow has been performed for } \\
\text { decades, since the company has been established } \\
\text { - Probably by asking them carefully if they have } \\
\text { gone over the company's policies. After } \\
\text { confirming, we will have more control about } \\
\text { whether returning the product or not } \\
\text { - So, we need to act fast in building that real-time } \\
\text { processes which will have } 80 \% \text { standardization } \\
\text { because we need to have } 20 \% \text { flexibility right at } \\
\text { the end of the day, we cannot have } 100 \% \text { straight } \\
\text { line. That doesn't work in any market }\end{array}$ \\
\hline
\end{tabular}

Table 2. Example of the coding process

We analysed the collected data using structural coding and thematic coding, suggested by Saldaña (2015). These two coding techniques complemented each other (Chancellor, Townson, 
\& Duffy, 2021; Wolff, Mahoney, Lohiniva, \& Corkum, 2019), and suited the way we segmented and analysed the collected data. In particular, we adopted structural coding to identify comparable segments of data across the interviewees' responses. Then, we adopted thematic coding on these segments to analyse detailed codes and synthesise them into themes. The analysis was managed using NVivo.

Data analysis followed a three-step procedure, of which an example is presented in Table 2. First, we performed structured coding to set up main dimensions and structural codes, which was based on the conceptual framework (see example in Table 2 column 1 and 2). These dimensions and structural codes help to organise the interviewees' responses into segments. Second, in each segment, we performed thematic coding. We created initial codes to label a section of interviewees' responses in relation to the structural codes. New codes were also allowed to emerge from the data (see example in Table 2 column 3 and 4). We note that certain data might be labelled by multiple codes. For instance, a paragraph in Table 2 was labelled as both push towards flexibility and pull against flexibility, which suggests an occurrence of the two forces. Third, we aggregated the codes into themes, nested under structural codes. Then, we compared and summarised the theme-related data across all interviews, which enabled us to find patterns and identify key findings.

We checked coding reliability through investigator triangulation. One researcher and one research assistant independently followed the coding procedure and coded the participant's responses, while another researcher randomly checked the coded items. Then, the researchers compared the results and discussed the differences until reaching a consensus. Our interview protocol and semi-structured questions ensured data reliability, as all interviews were conducted in a similar manner.

\section{Interview Results}

We now summarise the interview results, which are grouped into different categories: friction in realizing process flexibility and elements of friction; strengths of process stories in reducing friction; and context where process stories are most fit to increase process flexibility.

\subsection{Friction in realizing process flexibility}

Most participants acknowledged the occurrence of friction, pushing and pulling the flexibility of processes under their responsibility. Eight out of eleven participants commented on and gave concrete examples of both push and pull forces (Table 3). The experts highlighted that abstractions, standardizations, structures, and control rules defined in the business processes generated a significant pull against flexibility. They also noted that their organizations had been pushing towards process flexibility to cope with emergence, change, exceptions, and variations.

The common cases in the dataset can be presented in three patterns. First, when we started the conversation, the participants began by describing the standard workflows of selected processes (Expert A, B, D, F, G, H, I, and J). Most participants adopted linear sequences to explain standard workflows (e.g., "so step one is basically $[\ldots]$; the next step is that $[\ldots]$ " (Expert H) and "the returning process is simply a function of [...]," Expert D). These explanations were usually enriched with clarifications about control rules. For instance, when explaining a workflow for the product return, a participant also referred to the company's control policy: "Probably by asking them carefully if they have gone over the company's 
policies. After confirming, we will have more control about whether returning the product or not" (Expert D). For many participants, the standard workflow has been performed for years ("for decades, since the company has been established," Expert A), which suggests the resilience of standard structures and implies the hinder for flexibility. All in all, the first pattern highlights the existence of pull forces hindering flexible processes.

\begin{tabular}{|c|c|c|c|}
\hline Node/sub-node $(+)$ & $\begin{array}{l}\text { Expert } \\
\text { count } \\
(\mathrm{N}=11)\end{array}$ & Expert ID & Significant quotes \\
\hline \multicolumn{4}{|l|}{ Pull against flexibility } \\
\hline $\begin{array}{l}\text { Demands for abstraction, standards, } \\
\text { structure, and control rules }\end{array}$ & 8 & $\begin{array}{l}\text { A, B, D, F, G, H, } \\
\text { I, J }\end{array}$ & $\begin{array}{l}\text { "Let me tell you briefly about the whole } \\
\text { process in general [following with a standard } \\
\text { process description]" (Expert A) }\end{array}$ \\
\hline \multicolumn{4}{|l|}{ Push towards flexibility } \\
\hline $\begin{array}{l}\text { Demands for uncertainty, } \\
\text { emergence, change, exceptions, and } \\
\text { variations }\end{array}$ & 11 & $\begin{array}{l}\text { A, B, C, D, E, F, } \\
\text { G, H, I, J, K }\end{array}$ & $\begin{array}{l}\text { "When we operate the business process, } \\
\text { there's always an exception. There are always } \\
\text { things that the client asks out of the box" } \\
\text { (Expert G) }\end{array}$ \\
\hline $\begin{array}{l}\text { Standard processes do not capture } \\
\text { exceptions, looseness, variations, } \\
\text { adaptations, and evolutions }\end{array}$ & 6 & $\mathrm{~A}, \mathrm{C}, \mathrm{D}, \mathrm{E}, \mathrm{F}, \mathrm{H}, \mathrm{J}$ & $\begin{array}{l}\text { "Obviously it is a standard process showing } \\
\text { each step of what we need to do, and the } \\
\text { exceptions have not been shown here" (Expert } \\
\text { F) }\end{array}$ \\
\hline $\begin{array}{l}+ \text { Fostering new solutions with the use } \\
\text { of process story }\end{array}$ & 5 & $\mathrm{~B}, \mathrm{D}, \mathrm{F}, \mathrm{I}, \mathrm{J}$ & $\begin{array}{l}\text { "The most important part is, after reading this, } \\
\text { we have to find a solution to solve it" (Expert } \\
\text { B) }\end{array}$ \\
\hline
\end{tabular}

Table 3. Main findings regarding push vs pull in relation to process flexibility

The common cases in the dataset can be presented in three patterns. First, when we started the conversation, the participants began by describing the standard workflows of selected processes (Expert A, B, D, F, G, H, I, and J). Most participants adopted linear sequences to explain standard workflows (e.g., "so step one is basically [...]; the next step is that $[\ldots]$ " (Expert $\mathrm{H}$ ) and "the returning process is simply a function of [...]," Expert D). These explanations were usually enriched with clarifications about control rules. For instance, when explaining a workflow for the product return, a participant also referred to the company's control policy: "Probably by asking them carefully if they have gone over the company's policies. After confirming, we will have more control about whether returning the product or not" (Expert D). For many participants, the standard workflow has been performed for years ("for decades, since the company has been established," Expert A), which suggests the resilience of standard structures and implies the hinder for flexibility. All in all, the first pattern highlights the existence of pull forces hindering flexible processes.

The second pattern emerges when the participants discussed cases of exceptions/changes related to the standard workflows. All participants asserted they were facing uncertainty and change at the process analysis stage of the BPM lifecycle, which resulted in strong demands for exceptions, emergence, change, and variations (Experts A, B, C, D, E, F, G, H, I, J, and K). Exceptions were identified as the most important push towards process flexibility, which can be illustrated by these statements: "due to the characteristic of this business, there're so many exceptions" (Expert C); and "actually, there are countless of these situations. For example, [exception description]" (Expert D). Thereby, exceptions were regarded as an essential aspect of business operations. Further, as the interviews were conducted during the COVID-19 epidemic, changes, arising emergences, variations were viewed as a natural consequence of current business uncertainty (Experts A and I). For instance, "[there are] cases where you have 
to follow the process and cases where you can change" (Expert I). All these highlight that organizations are facing strong pushing forces towards process flexibility.

Interestingly, many participants recognised the co-existence of pull and push forces and suggested that friction is inherent to their business. This forms the third patterns, which can be further classified in two forms. On the one hand, many participants suggested the push towards flexibility as rising from limitations in the standard workflows: "although we need to follow standard process, we still always prepare a manual backup solution" (Expert D), "In fact in this specific job, [a] process is just a standard for us to base on when we do our job. But our job has a lot of exceptions" (Expert B); and "so this thing is just a standard and common process, and if you ask about exceptions, there are so many of them that I cannot tell you all" (Expert C). In this form, the push toward flexibility is intrinsic to the standard workflow. On the other hand, a few participants observed the demand to create standard workflows (or pull against flexibility) from occurring exceptions: "even though we call them exceptions, in theory, they still need to follow a standard process" (Expert C). Overall, the participants agreed on the existence of friction, which simultaneously involves pull and push towards process flexibility.

\section{Detailed picture of friction}

We now synthesize the interview findings into the conceptual framework (Section 3) in order to elaborate a more detailed picture of friction when realizing process flexibility. In particular, Figure 2 shows the detailed elements of the push towards and pull against process flexibility drawn from the interviews. It also presents two additional elements: understandability and representationality as relevant to the realization of process flexibility.

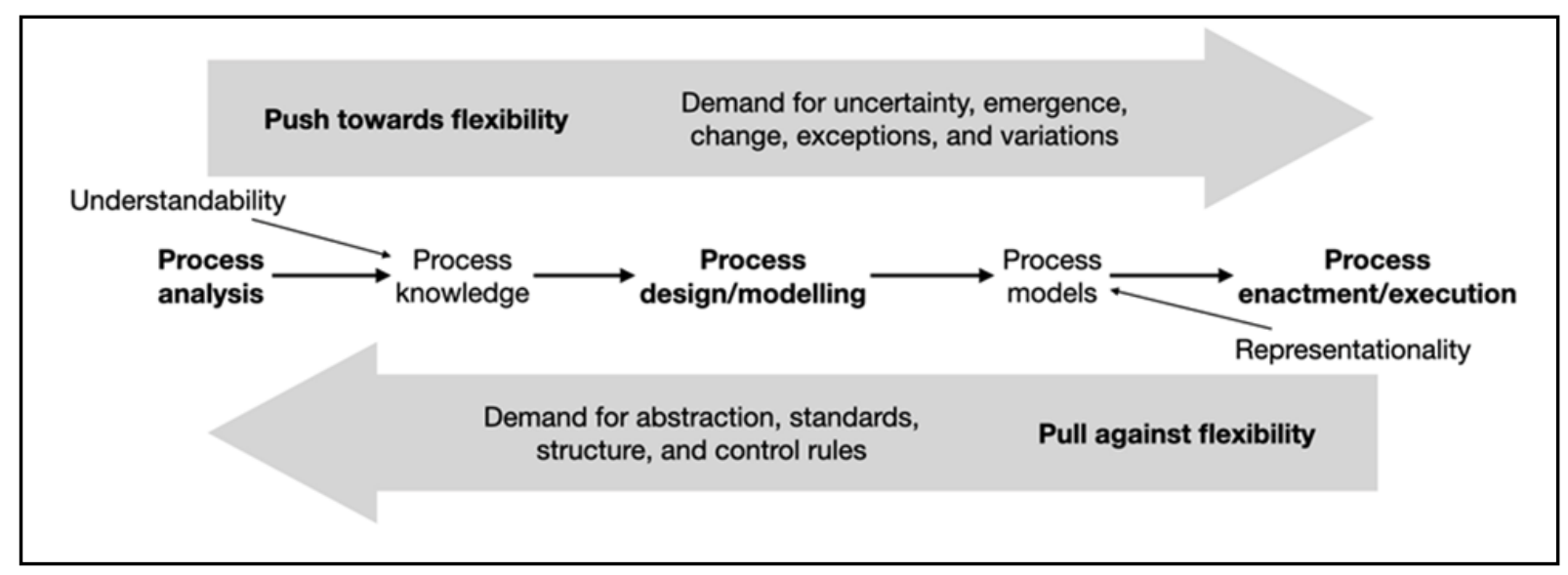

Figure 2. Elements of friction in realizing process flexibility

The push towards flexibility is essentially caused by organizations demanding for uncertainty, emergence, change, exceptions, and variations. Considering the BPM lifecycle, this push primarily impacts the analysis and design/modelling stages. These stages involve the need to capture knowledge regarding uncertainty, emergence, change, exceptions, and variations, which require BPM experts "[analysing] how we can solve this problem" (Expert F) and find ways to model more flexible processes. The push towards flexibility also impacts the enactment/execution stage. In particular, process models must consider exceptions and variations (Expert D, G, and I), which need to be handled in the enactment/execution stage (Cagnin \& Nakagawa, 2021). We further note that some experts in our interviews complained that their current process models do not/or cannot represent exceptions and variations: 
"obviously it is a standard process showing each step of what we need to do, and the exceptions have not been shown here" (Expert F).

Figure 2 also shows the detailed elements pulling against flexibility, which are caused by demands for abstraction, standards, structure, and control rules. It occurs in the opposite direction of the push force. Considering the BPM lifecycle, the pull relates to the need for predefined rules and controls required by the enactment and execution of business processes. Some experts suggested that even with software support for support dynamic, case-based and ad hoc changes, rules must be made explicit for their execution (Expert $C$ and $D$ ). This in turn constrains process design/modelling: "we need to create all this process because of the new requirements, new rules for the code" (Expert G). Furthermore, it also pulls against flexibility by demanding process knowledge to focus more on abstraction (e.g. understanding the process in general (Expert A, D, and G)), and standards (e.g. following the company's policies (Expert D, I, and J)).

Further, our interview findings indicate two additional elements as important to the realization of process flexibility: understandability and representationality. Related to understandability, the participants noted that it is important for the process knowledge to be understood. In particular, the participants mentioned the need to document the actual details of interruptions and exceptions. For instances, one must "understand the process they're doing" (Expert G) and that "I will find out where exactly the processes are interrupted, how it's been interrupted. After understanding everything, I will analyse how to fix the problem and also understand how difficult it is for other people" (Expert B). Understandability is also important in processes that require finding new solutions for emergent business problems. By acquiring such knowledge, BPM experts can then "redraw a whole new process" (Expert D). The lack of understandability may lead process models to go in erroneous directions, as "if they fall onto the exceptional scenario, they will just keep going straight without understanding about any other possible situations" (Expert D).

Related to representationality, six out of eleven participants indicated that the process models under their supervision were unable to capture and represent business operations in practice, then making it difficult to realize process flexibility. For instance, about a particular process model, one participant noted: "I mean, in this [current process model], there are many activities that happen but cannot be shown in the model" (Expert A). Processes need to be represented beyond the standard workflows, to include a variety of scenarios where standard workflows must be adapted to specific situations and needs.

In summary, Figure 2 provides a detailed picture of friction, with elements of push towards and pull against process flexibility along the BPM lifecycle. Figure 2 also highlights the roles of understandability and representationality in realizing of process flexibility, which are associated to process knowledge and process models, respectively.

\subsection{Strength of process stories in reducing friction}

This section reports on how process stories may contribute to reducing friction when dealing with process flexibility. Most participants asserted that process stories may help reducing friction by increasing the understandability and representationality of business processes (Table 4). 


\begin{tabular}{|c|c|c|c|}
\hline Node/sub-node (+) & $\begin{array}{l}\text { Expert } \\
\text { count } \\
(\mathrm{N}=11)\end{array}$ & Expert ID & Significant quotes \\
\hline \multicolumn{4}{|l|}{ Understandability } \\
\hline + In-depth look, understanding & 6 & $\begin{array}{l}\text { A, B, E, F, G, } \\
\text { J }\end{array}$ & $\begin{array}{l}\text { "[The] process story method is much more } \\
\text { specific; when you take a deeper look at the } \\
\text { story, you will understand how the situation } \\
\text { has happened" (Expert B) }\end{array}$ \\
\hline $\begin{array}{l}\text { Easy to express, } \\
\text { communication }\end{array}$ & 5 & A, C, F, I, J & $\begin{array}{l}\text { "When we go more in-depth to understand } \\
\text { the process, it is obvious that this one } \\
\text { [process story] is better" (Expert A). }\end{array}$ \\
\hline $\begin{array}{l}+ \text { Provide reasons behind } \\
\text { business operations }\end{array}$ & 4 & $\mathrm{D}, \mathrm{H}, \mathrm{I}, \mathrm{J}$ & $\begin{array}{l}\text { "The thing I like about the storytelling } \\
\text { method is that it helps me to understanding } \\
\text { the reason of each step which leads to the } \\
\text { next one" (Expert B) }\end{array}$ \\
\hline $\begin{array}{l}+ \text { Real-life visualised } \\
\text { communication }\end{array}$ & 3 & $\mathrm{~B}, \mathrm{H}, \mathrm{I}$ & $\begin{array}{l}\text { "They can imagine themselves in this } \\
\text { situation. and when a similar situation is } \\
\text { happening in real life, they have already a } \\
\text { solution to solve it" (Expert B) }\end{array}$ \\
\hline \multicolumn{4}{|l|}{ Representationality } \\
\hline $\begin{array}{l}\text { + Capture exceptions, } \\
\text { looseness, variations, } \\
\text { adaptations and evolutions }\end{array}$ & 8 & $\begin{array}{l}A, B, D, E, F, \\
G, H, K\end{array}$ & $\begin{array}{l}\text { "For example, at the refund step, the [BPMN] } \\
\text { chart won't be able to show me how the } \\
\text { system stops working, but the storytelling } \\
\text { method will tell me exactly how" (Expert D) }\end{array}$ \\
\hline + Provide detail & 7 & $\begin{array}{l}\text { A, B, C, D, E, } \\
\text { F, H }\end{array}$ & $\begin{array}{l}\text { "In the story, you describe in detail many } \\
\text { situations like how to estimate the demand, } \\
\text { how to stock inventory, and receive } \\
\text { customer's order" (Expert H) }\end{array}$ \\
\hline $\begin{array}{l}+ \text { High-level representation of } \\
\text { real operations }\end{array}$ & 7 & $\begin{array}{l}\text { A, C, F, G, H, } \\
\text { I, J }\end{array}$ & "It is relevant much to reality" (Expert F) \\
\hline
\end{tabular}

Table 4. Main findings regarding how process stories help process understandability and representation

Regarding understandability, the participants highlighted different aspects of process stories that make process flexibility easier to analyse: in-depth look on the business operations, easy to express, real-life visualised communication, and providing reasons behind business operations. The most commented aspect was that process stories can provide an in-depth look over the business operations and taking flexibility into consideration. For instance, a participant noted "I think it includes more information and various circumstances in more detail" (Expert F); and others noted "they [process stories] can have further details to help understand [the process]" (Expert E). This in-depth look at business processes brought by process stories also comes from the ability to capture operational contexts (Expert B and E).

Five participants indicated that process stories are easy to express. By integrating narratives, process stories "do not constraint the way business scenarios are presented, and thus it is easier to express their tasks and ideas" (Expert A). This is further supported by another key statement: "in the storytelling what you're doing is you're just explaining it in a simple way to make it easier for your team to understand" (Expert I).

Experts D, H, I, and J highlighted another important strength of process stories, which is providing reasons behind certain business operations. In a common case of process flexibility, it is not just the workflow that adapts, the workers involved in the process also must adapt. Here, process stories can provide reasons for the uncertainty and change demands, and thus 
contribute to convince workers to become more involved in process adaptations and evolutions. In this regard, expert I noted "I think storytelling will be helpful. Why? Because as a team member, If I don't get a bigger picture, I would just say why, why don't we follow this? This has been followed for several years. So, the objective of storytelling is to really convince my team that whatever we are doing has a reason why. It is much easier to get their buy-in." In a similar vein, expert $G$ highlighted process stories can help to justify "what benefit this process brings in not only for the business perspective but also for the people perspective."

Three experts further suggested that process stories can also support real-life visualised communication, "by using visual images to show the staffs how to do their job so that they can understand easier" (Expert $\mathrm{H}$ ). This aspect is important in training when one wants to explain the business operations to others, as seen via "storytelling is used for training of each procedure and to express the message to other people more effective because it has been visualised" (Expert H). An expert also favoured process stories for their visual images: "I think the story telling, as it could include the image and also show more details" (Expert F).

Regarding representationality, the participants highlighted three aspects related to process stories. First, eight participants agreed that process stories can capture variations. When the participants were asked to compare process stories with the BPMN models of processes under their responsibility, they asserted that process stories can cover more cases (Expert A, B and D). One expert noted that "this one [process story] can show more, because this one [BPMN model] is just only a chart. Less words cannot express more cases" (Expert C). In a similar vein, Expert K noted that "process stories are more appropriate, as there can be many variations in the business process. The company would try to collect as much as possible all information and insights from customers to have a more convincing consultation process by hitting those points collected from the customers."

Furthermore, process stories were also seen by the participants as a way to document exceptions not present in the BPMN models. As noted by two participants, "at the refund step, the [BPMN] chart won't be able to show that the system stopped working, but the storytelling method will tell us exactly that" (Expert D), and "in the process story, there are some situations or exceptions that do not exist here [in the BPMN model]" Expert (C).

Seven participants suggested that process stories also provide useful details about business processes. In particular, they noted that process stories show the interactions between the stakeholders in the business operations (Expert E), provide details on the sequence of operations (Expert D and F), and accommodate flexible ways to sequence operations (Expert A and B). In fact, one expert exclaimed: "to me, the process story method is so detailed. The first thing is the interactions with the customers. This is the first information about solving a request, it shows how the case was done and the whole story about the situation" (Expert E).

Seven participants also suggested that process stories are highly representative of real business operations. On the one hand, process stories support the representation of routine operations by "showing how the sequence of each step or how the process will happen, so it helps people imagine the process easier" (Expert F). On the other hand, they support non-routine operations through the representation of exceptions, variations, adaptations, and emergent cases. As commented by two participants, "this one [process story] can show more [exceptions] (Expert C) and "it shows how the cases were done and the whole story about the situation" (Expert E). Seen together, process stories enable us to represent business operations in a way closer to reality. 
In summary, the participants highlighted different aspects of process stories supporting understandability and representationality in relation to reducing friction (Figure 3). The reduction of friction operates in two directions. First, process stories increase the understandability of process knowledge, which pushes towards better design of process flexibility. Second, process stories increase the representationality of process models, bringing them closer to reality. This reduces the pull against flexibility caused by inflexible process models and corresponding enactments/executions.

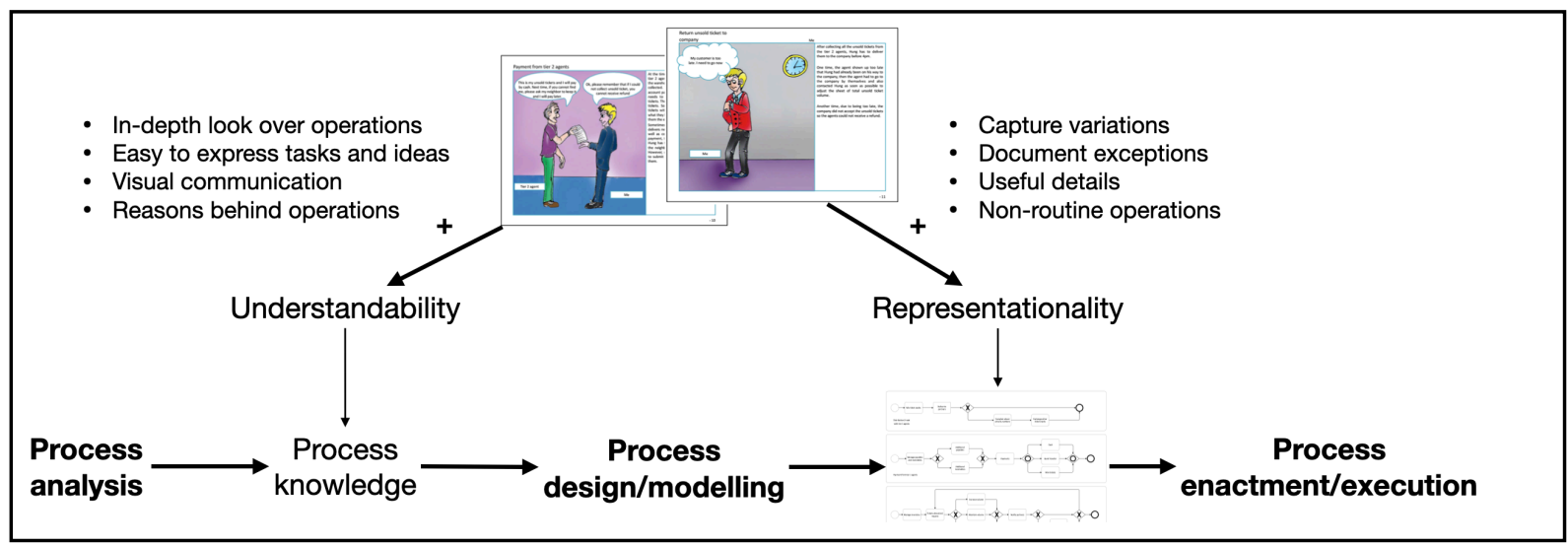

Figure 3. Roles of process stories in reducing friction

\subsection{Context where process stories may be most fit (or unfit)}

Another important result was the identification of contexts where process stories may be most fit (or unfit). Table 5 summarises these contexts.

The interviewed participants suggested that process stories may be most fit in three contexts. First, process stories are useful where the process needs complementarity of abstraction and detail. All participants asserted the combination of process stories and BPMN models provides abstraction with useful details, which can be illustrated through two notes: "this model [BPMN] provides us a big picture while this one [storytelling] gives us more details of the process" (Expert A); and "if I want to show them the general plan, I will use the diagram from the BPMN method, to help them understand what they have to do in the near future. But if I need something more specific, I will use the process story method" (Expert B). Regarding how to use this combination, some participants suggested starting with BPMN models to get an overall picture, and then using process stories for details: "the [BPMN] diagram is general, right? from this we will go to details [process stories]" (Expert F).

In this combination, we note a practical point, that most organizations may already have BPMN models (or similar models) for their main processes (Cognini et al., 2018). Thus, process stories can serve as an add-on to existing BPMN (or similar) models, which together provide both the big picture and the details about business processes. Further, the combination of BPMN models and process stories is aligned with the current movement towards hybrid approaches to process modelling, which "allow overcoming the limitations of individual languages and maintaining the balance between understandability and flexibility" (Andaloussi et al., 2020, p. 8). 


\begin{tabular}{|c|c|c|c|}
\hline Node/sub-node (+) & $\begin{array}{l}\text { Expert } \\
\text { count } \\
(\mathrm{N}=11)\end{array}$ & Expert ID & Significant quotes \\
\hline \multicolumn{4}{|c|}{ Context where process stories is most fit } \\
\hline $\begin{array}{l}+ \text { Complementarity of } \\
\text { abstraction (big picture) and } \\
\text { detail }\end{array}$ & 11 & $\begin{array}{l}\text { A, B, C, D, E, F, } \\
G, H, I, J, K\end{array}$ & $\begin{array}{l}\text { "BPMN method is mostly about a general } \\
\text { view, where the process stories method is } \\
\text { more specific about the situation" (Expert B) }\end{array}$ \\
\hline $\begin{array}{l}+ \text { Describe different } \\
\text { situations, scenarios }\end{array}$ & 5 & A, C, F, H, J & $\begin{array}{l}\text { "If we need more subprocesses, this one } \\
\text { [storytelling] is needed. And if we need to } \\
\text { know further details and know what is right or } \\
\text { wrong, we also need this one [storytelling]" } \\
\text { (Expert A) }\end{array}$ \\
\hline + Handling exceptions & 5 & A, D, G, I, J & $\begin{array}{l}\text { "It [process stories] has the details on each step } \\
\text { of the exceptional cases. For example, there'll } \\
\text { be some notes about exceptions, and it'll guide } \\
\text { you on how to solve the case" (Expert D) }\end{array}$ \\
\hline \multicolumn{4}{|c|}{ Complaints experienced by the participants (-) } \\
\hline $\begin{array}{l}\text { Requires more effort } \\
\text { reading }\end{array}$ & 3 & $\mathrm{C}, \mathrm{D}, \mathrm{H}$ & $\begin{array}{l}\text { "If talking about my idea, I would prefer the } \\
\text { simple and fast model diagram; because } \\
\text { storytelling requires me to read a lot, so many } \\
\text { words" (Expert } \mathrm{H} \text { ) }\end{array}$ \\
\hline $\begin{array}{l}\text { - Shows too many details } \\
\text { and loses the main idea }\end{array}$ & 2 & $\mathrm{D}, \mathrm{H}$ & $\begin{array}{l}\text { "Once I see too many exceptions in stories, } \\
\text { then I cannot catch up the main idea of the } \\
\text { process anymore" (Expert D) }\end{array}$ \\
\hline - $\quad$ Time consuming & 2 & $\mathrm{~A}, \mathrm{C}$ & $\begin{array}{l}\text { "This one [storytelling] is more appropriate } \\
\text { because people can easily understand; but it } \\
\text { would take time to read" (Expert A) }\end{array}$ \\
\hline
\end{tabular}

Table 5. Main findings regarding context where process stories are most fit, and complaints experienced by the participants

Second, process stories facilitate the description of cases and scenarios. The method fosters "using visual images to show the staff how to do their job so that they can understand easier" (Expert H). Further, the method also supports situation description with example stories, as noted by two experts: "so what we get is a story in each scenario" (Expert E) and "the stories you have describe in detail many situations like [situation description]" (Expert H). Interestingly, the method enables different perspectives over a business process. In our interviews, we noted a case of two experts from the same company having different views over the same process. Using process stories, Expert D and E described the same workflow from their personal perspectives and contributed different situations and scenarios regarding the workflow.

Third, process stories show strengths in handling exceptions. As process stories take the users' viewpoints, they can represent exceptional situations and different solutions developed by the users to handle the situations. Two experts clarified "I think this process story is an interesting method, it concretizes the problem that happens at that time and how we can solve that problem" (Expert F), and "the most important part is after reading this [process story] we have to find a solution to solve it" (Expert B). Other experts further noted that this capability is 
especially relevant during the COVID epidemic: "regarding COVID, you really must apply this model [process story]. People need to see how it happens with the company. So, you need to tell them" (Expert G).

On the other hand, the interviewed participants also identified three concerns regarding the use of process stories in realizing flexible processes: process stories require more effort analysing the process (Expert $\mathrm{C}, \mathrm{D}$ and $\mathrm{H}$ ); they show too many details and thus the reader loses the main idea (Expert $\mathrm{D}$ and $\mathrm{H}$ ); and readers consume more time analysing them (Expert A and C). We illustrate these issues with three quotes: "Storytelling requires me to read a lot, so many words" (Expert H); "once we show too many exceptions in this story, then I cannot catch up the main idea of the writer anymore" (Expert D); and "when you look at it, you can imagine steps in detail, but the story method requires more time read" (Expert C). These issues can be explained, if we consider the variety of exceptions being modelled, which lead to a large set of stories being defined for a single business process. As a result, many participants have suggested the complementarity of process stories and BPMN models, but not the substitution of one for the other.

In summary, our main findings are threefold. First, there is evidence regarding the occurrence of friction in realizing flexible processes, where the participants characterized both the push and pull forces (Table 3). Based on that, we further identified and characterized the elements of friction in realizing flexible processes across the BPM lifecycle (Figure 2). Second, process stories can reduce friction by improving the understandability of process knowledge and the representationality of process models (Figure 3 and Table 4). Third, there are contexts where process stories may be most fit (or unfit). Table 5 summarises these contexts considering the participants' feedback.

\section{Discussion}

Disruptive business environments pose enormous risks as well as opportunities for organizations. Both established industry leaders and small businesses must adapt and evolve to stay competitive, which highlights the importance of the realization of process flexibility (Cognini et al., 2018; Thuan et al., 2020). This study offers several research contributions towards this endeavour.

\subsection{An analytical lens for understanding friction when realizing flexible processes}

The study introduces friction as a metaphor to understand the realization of process flexibility. While previous studies have related process modelling and process flexibility from singular angles (design versus use, structured versus unstructured, complexity versus simplicity, control versus value, and technical versus social), our view takes a holistic perspective, as friction caused by two opposing forces: one pushes towards flexibility while the other pulls against flexibility. The interview results provide empirical evidence supporting this notion of friction in the realization of flexible processes. As a result, a conceptual framework has been elaborated with the main elements of friction (Figure 2), which serves as an analytical lens for understanding process flexibility in the BPM lifecycle.

With the main elements of friction, BPM experts are expected to understand how the demand for flexibility manifests in the process analysis stage and is pushed to the design/modelling and enactment/execution stages. The push for flexibility involves certain elements: 
uncertainty, emergence, change, exceptions, and variations. In addition, BPM experts are also required to understand how the pull against flexibility manifests in the process enactment/execution stage and is pulled back the design/modelling and analysis stages. The pull against flexibility involves certain elements: abstraction, standards, structure, and control rules.

Overall, experts "must move away from their singular systems viewpoint" (Hayes et al., 2011, p. 174) to focus on the entire BPM lifecycle and diversity of intervening forces. Our work introduces a holistic framework, which highlights the push-pull relationships and details the elements of friction involved.

\subsection{Process stories as a useful method for analysing and designing flexible processes}

Process stories can be used as a method for designing flexible processes. The interview results indicate that process stories help BPM experts understand process knowledge, with particular focus on real-world operations (Table 4); and such understanding reduces friction when realizing flexible processes. Positioning the interview results with recent studies, we can further suggest that process stories help bringing personal experiences with the process. They narrate a combination of structured and unstructured events, providing context to the workflows (Antunes et al., 2020; Simões et al., 2018). They can narrate complex situations using simple scenarios and narratives. They can mix control structures with value-oriented goals and behaviours. Finally, process stories can also mix the technical with the social aspects of process realization (Antunes et al., 2019).

Considering different types of process flexibility, process stories can be used, to some extent, to foster flexibility by design, flexibility by deviation, flexibility by under-specification, and flexibility by change (Schonenberg, Mans, Russell, Mulyar, \& van der Aalst, 2008). In the first type, process stories help identify alternative execution scenarios and allow them to be incorporated in the process model at design time (see Table 5 regarding 'describe different situations, scenarios'). In the second type, process stories help identify occasional, unforeseen behaviours (see Table 4 regarding 'capture exceptions, looseness, variations, adaptations and evolutions'). Here, we note that, by combining process stories and BPMN models, the method does not require altering the existing process models. In the third type, process stories contribute to understand and represent flexibility under specifications (see Table 4), where only at execution time a specific scenario can be selected. In the last type, process stories motivate flexibility by changing the viewpoints and accommodating with alternative narratives. The method handles occasional and permanent unforeseen behaviours, fostering exception handling and problem-solving (see Table 5 regarding 'Handling exceptions').

As mentioned above, there is no one-size-fits-all modelling solution for realizing flexible processes. Our findings shed light on the specific contexts in which process stories are most fit (Table 5). Process stories should be used to understand different situations and scenarios, forming a holistic picture of the organization's particular demands for flexibility, and then using such knowledge to design and model business processes in a way that represents the specific demands for flexibility, e.g., highlighting variations and exceptions. The combination of BPMN models and process stories brings benefits to the BPM lifecycle, as both support process understandability and representationality. For instance, while BPMN models represent the routine aspects of a business process (the "happy path"), process stories represent variant business situations and exceptions, and provide relevant contextual 
knowledge. This is aligned with the current trend of using hybrid approaches for addressing process flexibility (Andaloussi et al., 2020).

\subsection{Implications for process enactment/execution}

We note that process stories primarily concern the analysis and design/modelling stages of the BPM lifecycle. Thus, this study differs from previous studies focusing on the enactment/execution stage, where the main goal is to develop software approaches supporting the enactment and execution of flexible processes (Braun et al., 2016; Hallerbach et al., 2010; Sid et al., 2019). We further note that the analysis and design/modelling stages are logical antecedents of the enactment/execution stage (Haseeb et al., 2019). Only by properly capturing and representing flexible scenarios, the corresponding flexible processes can be enacted and executed.

In this regard, we identify two limitations of the current study. First, we do not discuss if/how process stories can be technically integrated with BPMN (or similar) models. Such technical integration would extend the ways process-aware information systems can automate and control flexible processes, for instance, by supporting the coherent execution of alternative and conflicting stories. This technical integration is an interesting topic for future work. Our contribution lies in the discussion of the antecedents of such integration, which involve the understandability and representationality properties.

Second, even though we discuss process flexibility throughout the BPM lifecycle, the actual execution of process flexibility is left for future work. In particular, we do not propose and validate a method for analysing, designing, enacting, monitoring, and improving flexible business processes. Nevertheless, we provide the foundations for developing such a method, considering in particular:

- Articulation of process analysis, design, and modelling, so that BPM experts better understand the forces imposed by the "happy path" across the various realization stages.

- Provide BPM experts with conceptual scaffolding required to design or redesign more flexible processes.

- Highlight relevant properties (understandability and representationality) to assess the realization of process flexibility.

\subsection{Implications for research and practice}

This study enriches the literature of process stories in BPM. Existing studies have adopted storytelling for analysing and representing business processes (Bauer, 2019; Haggège \& Vernay, 2019), and examined process stories and process flexibility from a theoretical perspective (Antunes et al., 2019; Hayes et al., 2011). This study extends those findings with empirical evidence regarding the benefits of process stories in reducing friction in realizing flexible processes. In this context, process stories can improve the understandability of process knowledge and the representationality of process models.

To BPM managers and practitioners, this study suggests that process stories are useful in the early stages of the BPM life cycle. Our findings further suggest contexts in which process stories are most suitable and highlight some complaints experienced by BPM experts (Table 5). These insights provide practical guidelines for using process stories in analysing and 
designing/modelling flexible business processes. In addition, it is worthwhile to note that process stories can be used in combination with BPMN models. This helps reducing overhead for organizations, as the addition of process stories does not require organizations to replace existing process modelling, enactment, and execution technologies.

\section{Conclusion}

We began our research with the observation that organizations face increasing push towards process flexibility, while they also face significant pull against process flexibility. Thus, there is a strong need for understanding the interactions between the two forces. Addressing this gap, this research proposes the use of process stories in understanding friction throughout the BPM lifecycle. We explore this proposition using a series of in-depth interviews with BPM experts. The results show that process stories help reducing friction by increasing the understandability and representationality of business processes. Our findings align with Cognini et al. (2018), confirming that the realization of process flexibility has to be addressed in all stages of the BPM lifecycle. Although process stories have already been used to analyse business processes (Antunes et al., 2020; Haggège \& Vernay, 2019), this research is a pioneer in considering process stories to address friction when realizing flexible processes.

Regarding future research directions, we observe from the interviews that modelling processes with visual stories are cognitively demanding, which suggests further investigation into how to ease such cognitive demand (Haggège \& Vernay, 2019). Future research should also explore the cognitive differences between showing participants BPMN models and process stories. Another direction for future research involves the semantic and syntactic integration of process stories and BPMN (or similar) models. To generalize our results, future case studies could assess the use of process stories in different stages of the BPM lifecycle. Another possible direction could be to extend the time frame of the research. As this study was conducted in a period highly influenced by the COVID-19 pandemic, it would be interesting to investigate friction (pulling and pushing towards process flexibility) in a longitudinal study.

\section{Acknowledgments}

This work was supported by RMIT University Vietnam (ref. IRG 2022 - Grant 12) and LASIGE Research Unit (ref. UIDB/00408/2020).

\section{References}

Afflerbach, P., Kastner, G., Krause, F., \& Röglinger, M. (2014). The business value of process flexibility. Business \& Information Systems Engineering, 6(4), 203-214.

Andaloussi, A. A., Burattin, A., Slaats, T., Kindler, E., \& Weber, B. (2020). On the declarative paradigm in hybrid business process representations: A conceptual framework and a systematic literature study. Information Systems, 91, 101505.

Antunes, P., Pino, J. A., Tate, M., \& Barros, A. (2020). Eliciting Process Knowledge Through Process Stories. Information Systems Frontiers, 22(5), 1179-1201. doi:https://doi.org/10.1007/s10796-019-09922-0

Antunes, P., Tate, M., \& Pino, J. A. (2019). Business Processes and Flexibility: A Theoretical Perspective. Proceedings of the Australasian Conference on Information Systems, Fremantle, Australia, 64-74. https://aisel.aisnet.org/acis2019/7 
Aysolmaz, B., Schunselaar, D. M., Reijers, H. A., \& Yaldiz, A. (2019). Selecting a process variant modeling approach: guidelines and application. Software $\mathcal{E}$ Systems Modeling, 18(2), 1155-1178.

Bareil, C. (2013). Two Paradigms about Resistance to Change. Organization Development Journal, 31(3), 59-71.

Bauer, T. (2019). Pre-Modelled Flexibility for Business Processes. Proceedings of the 21st International Conference on Enterprise Information Systems, Crete, Greece, 547-555.

Bernardo, R., Galina, S. V. R., \& de Pádua, S. I. D. (2017). The BPM lifecycle. Business Process Management Journal, 23(1), 155-175.

Boudreau, M. C., \& Robey, D. (1996). Coping with contradictions in business process reengineering. Information Technology \& People, 9(4), 40-57.

Braun, R., Schlieter, H., Burwitz, M., \& Esswein, W. (2016). BPMN4CP Revised--Extending BPMN for Multi-perspective Modeling of Clinical Pathways. Proceedings of the 49th Hawaii International Conference on System Sciences (HICSS), 3249-3258.

Cagnin, M. I., \& Nakagawa, E. Y. (2021). Towards dynamic processes-of-business processes: a new understanding. Business Process Management Journal, 27(5), 1545-1568.

Chancellor, C., Townson, L., \& Duffy, L. (2021). Destination ambassador programs: Building informed tourist friendly destinations. Journal of Destination Marketing $\mathcal{E}$ Management, $21,100639$.

Cognini, R., Corradini, F., Gnesi, S., Polini, A., \& Re, B. (2018). Business process flexibility-a systematic literature review with a software systems perspective. Information Systems Frontiers, 20(2), 343-371.

Creswell, J. W. (2009). Research design: Qualitative, quantitative, and mixed methods approaches (3 ed.): SAGE Publications, Thousand Oaks, California.

Davenport, T. H. (2005). The coming commoditization of processes. Harvard Business Review, 83(6), 100-108.

de Albuquerque, J. P., \& Christ, M. (2015). The tension between business process modelling and flexibility: Revealing multiple dimensions with a sociomaterial approach. The Journal of Strategic Information Systems, 24(3), 189-202.

de Morais, R. M., Kazan, S., de Pádua, S. I. D., \& Costa, A. L. (2014). An analysis of BPM lifecycles: from a literature review to a framework proposal. Business Process Management Journal, 20(3), 412-432.

Dumas, M., La Rosa, M., Mendling, J., \& Reijers, H. A. (2018). Fundamentals of Business Process Management (2 ed.): Springer, Berlin, Germany.

Feldman, M. S., \& Pentland, B. T. (2003). Reconceptualizing organizational routines as a source of flexibility and change. Administrative science quarterly, 48(1), 94-118.

Fischer, M., Imgrund, F., Janiesch, C., \& Winkelmann, A. (2020). Strategy archetypes for digital transformation: Defining meta objectives using business process management. Information \& Management, 57(5), 103262. doi: https://doi.org/10.1016/j.im.2019.103262

Gross, S., Stelzl, K., Grisold, T., Mendling, J., Röglinger, M., \& vom Brocke, J. (2021). The Business Process Design Space for exploring process redesign alternatives. Business Process Management Journal, 27(8), 25-56. doi: https://doi.org/10.1108/BPMJ-03-20200116

Haggège, M., \& Vernay, A.-L. (2019). Story-making as a method for business modelling. Business Process Management Journal, 26(1), 59-79. doi:10.1108/BPMJ-12-2017-0363 
Hallerbach, A., Bauer, T., \& Reichert, M. (2008). Managing process variants in the process lifecycle. Proceedings of 10th International Conference on Enterprise Information Systems, Barcelona, Spain, 154-161.

Hallerbach, A., Bauer, T., \& Reichert, M. (2010). Capturing variability in business process models: the Provop approach. Journal of Software Maintenance and Evolution: Research and Practice, 22(6-7), 519-546.

Haseeb, J., Ahmad, N., Malik, S. U., \& Anjum, A. (2019). Application of formal methods to modelling and analysis aspects of business process reengineering. Business Process Management Journal, 26(2), 548-569.

Hayes, G. R., Lee, C. P., \& Dourish, P. (2011). Organizational routines, innovation, and flexibility: The application of narrative networks to dynamic workflow. International journal of medical informatics, 80(8), e161-e177.

Hidri, W., M'tir, R. H., Saoud, N. B. B., \& Ghedira-Guegan, C. (2019). A Meta-model for context-aware adaptive Business Process as a Service in collaborative cloud environment. Procedia Computer Science, 164, 177-186.

Javidroozi, V., Shah, H., \& Feldman, G. (2019). A framework for addressing the challenges of business process change during enterprise systems integration. Business Process Management Journal, 26(2), 463-488.

Krumeich, J., Weis, B., Werth, D., \& Loos, P. (2014). Event-Driven Business Process Management: where are we now?: A comprehensive synthesis and analysis of literature. Business Process Management Journal, 20(4), 615-633.

Leite, F., Antunes, P. A. M., Guimarães, N., \& Pino, J. A. (2019). Method supporting the adoption of visual stories in judicial systems. Proceedings of the 27th European Conference on Information Systems (ECIS), Stockholm and Uppsala, Sweden, Paper 73.

Marcinkowski, B., \& Gawin, B. (2019). A study on the adaptive approach to technology-driven enhancement of multi-scenario business processes. Information Technology $\mathcal{E}$ People, 31(1), 118-146.

Mejri, A., Ghannouchi, S. A., \& Martinho, R. (2016). Representing Business Process Flexibility using Concept Maps. Procedia Computer Science, 100, 1260-1268.

Miles, M. B., Huberman, A. M., \& Saldaña, J. (2014). Qualitative data analysis: A methods sourcebook: SAGE Publications, Thousand Oaks, California.

Münstermann, B., Eckhardt, A., \& Weitzel, T. (2010). The performance impact of business process standardization: An empirical evaluation of the recruitment process. Business Process Management Journal, 16(1), 29-56.

Qu, W. G., Ding, Y., Shou, Y., Zhou, H., \& Du, H. (2014). The impact of enterprise systems on process flexibility and organisational flexibility. Enterprise Information Systems, 8(5), 563-581.

Recker, J., \& Mendling, J. (2016). The state of the art of business process management research as published in the BPM conference. Business \& Information Systems Engineering, 58(1), 55-72.

Reichert, M. (2018). Enabling Flexible and Robust Business Process Automation for the Agile Enterprise. In Gruhn V., Striemer R. (eds) The Essence of Software Engineering (pp. 203220): Springer, Cham.

Reichert, M., Hallerbach, A., \& Bauer, T. (2015). Lifecycle management of business process variants. In Handbook on Business Process Management 1 (pp. 251-278): Springer.

Reichert, M., \& Weber, B. (2012). Enabling flexibility in process-aware information systems: challenges, methods, technologies: Springer Science \& Business Media, Berlin, Germany. 
Rettig, C. (2007). The Trouble with Enterprise Software. MIT Sloan Management Review, 49(1), 21-27.

Romero, H. L., Dijkman, R. M., Grefen, P. W., \& van Weele, A. J. (2015). Factors that determine the extent of business process standardization and the subsequent effect on business performance. Business \& Information Systems Engineering, 57(4), 261-270.

Rosa, M. L., van der Aalst, W. M. P., Dumas, M., \& Milani, F. P. (2017). Business process variability modeling: A survey. ACM Computing Surveys (CSUR), 50(1), 1-45.

Rosemann, M., \& Recker, J. (2006). Context-aware process design: Exploring the extrinsic drivers for process flexibility. Proceedings $18^{\text {th }}$ International Conference on Advanced Information Systems Enginnering, Namur University Press, Belgium, 149-158.

Saldaña, J. (2015). The coding manual for qualitative researchers: Sage, Thousand Oaks, California.

Saunders, B., Sim, J., Kingstone, T., Baker, S., Waterfield, J., Bartlam, B., . . J Jinks, C. (2018). Saturation in qualitative research: exploring its conceptualization and operationalization. Quality \& Quantity, 52(4), 1893-1907.

Schäfermeyer, M., Rosenkranz, C., \& Holten, R. (2012). The impact of business process complexity on business process standardization. Business $\mathcal{E}$ Information Systems Engineering, 4(5), 261-270.

Schonenberg, H., Mans, R., Russell, N., Mulyar, N., \& van der Aalst, W. M. P. (2008). Process flexibility: A survey of contemporary approaches. In Advances in enterprise engineering $I$ (pp. 16-30): Springer, Berlin, Germany.

Sid, I., Reichert, M., \& Ghomari, A. R. (2019). Enabling flexible task compositions, orders and granularities for knowledge-intensive business processes. Enterprise Information Systems, 13(3), 376-423.

Simchi-Levi, D., Wang, H., \& Wei, Y. (2018). Increasing supply chain robustness through process flexibility and inventory. Production and Operations Management, 27(8), 14761491.

Simões, D., Antunes, P., \& Carriço, L. (2018). Eliciting and modeling business process stories. Business \& Information Systems Engineering, 60(2), 115-132.

Simões, D., Thuan, N. H., Jonnavithula, L., \& Antunes, P. (2015). Modelling Sensible Business Processes. In T. K. Dang, R. Wagner, J. Küng, N. Thoai, M. Takizawa, E E. Neuhold (Eds.) Future Data and Security Engineering (Vol. 9446, pp. 165-182): Springer International Publishing, Switzerland.

Svejvig, P., \& Jensen, T. B. (2013). Making sense of enterprise systems in institutions: a case study of the re-implementation of an accounting system. Scandinavian Journal of Information Systems, 25(1), 3-36.

Thuan, N. H., Phuong, H. A., George, M., Nkhoma, M., \& Antunes, P. (2020). Toward an Ontology for Improving Process Flexibility. In Dang T.K., Küng J., Takizawa M., Chung T.M. (eds) Future Data and Security Engineering (pp. 411-428). Cham: Springer International Publishing, Switzerland.

Tregear, R. (2015). Business process standardization. In vom Brocke \& Rosemann M. (eds) Handbook on Business Process Management 2 (pp. 421-441): Springer, Berlin, Germany.

van der Aalst, W. M. P. (2013). Business process management: a comprehensive survey. International Scholarly Research Notices, 2013. doi:http://dx.doi.org/10.1155/2013/507984

van der Aalst, W. M. P., Pesic, M., \& Schonenberg, H. (2009). Declarative workflows: Balancing between flexibility and support. Computer Science-Research and Development, 23(2), 99113. 
van der Aalst, W. M. P., Ter Hofstede, A. H., \& Weske, M. (2003). Business process management: A survey. In van der Aalst W.M.P. \& Weske M. (eds) Proceedings of international conference on business process management 2003, Eindhoven, The Netherlands, 1-12.

Venable, J., Pries-Heje, J., \& Baskerville, R. (2016). FEDS: a framework for evaluation in design science research. European Journal of Information Systems, 25(1), 77-89.

Vom Brocke, J., Recker, J., \& Mendling, J. (2010). Value-oriented process modeling: integrating financial perspectives into business process re-design. Business Process Management Journal, 16(2), 333-356.

Wolff, B., Mahoney, F., Lohiniva, A. L., \& Corkum, M. (2019). Collecting and analyzing qualitative data. The CDC Field Epidemiology Manual; Oxford University Press: Oxford, UK; New York, NY, USA, 213-228.

Zelt, S., Recker, J., Schmiedel, T., \& vom Brocke, J. (2019). A theory of contingent business process management. Business Process Management Journal, 25(6), 1291-1316.

\section{Appendix A: Semi-structured questions for the interview}

\section{Section 1: General information about their business processes.}

1. Tell me about the business process(es) that you have already participated

2. Can you describe your roles in the(se) process(es)?

a. For how long?

3. In the(se) process(es), do you face any issues regarding the process changes, unique cases and exceptions

\section{Section 2: Exploring process flexibility in selected business processes}

[Show the participants selected processes modelled according to BPMN models]

4. Do you know if the process is followed as described?

5. In what circumstances do you see standard processes?

6. In what circumstances do you see variations?

7. How do you handle flexibility of these processes?

8. For what reason do you see those variations? Do you document variations? Why not?

9. Are there cases where the process fails, and you have to improvise? What happens when you improvise?

\section{Section 3A: Process stories in the realization of process flexibility}

[Show the participants processes modelled according to process stories]

10. How process stories accommodate standard processes?

11. How process stories accommodate process variations?

12. How do you compare the stories model to BPMN?

13. Do the stories better represent your real business process?

14. How these process stories handle changes, unique cases and exceptions?

15. Did/does the proposed method lead you to any additional new way to change/adapt your business processes? Can you explain these changes/adaptations? 


\section{Section 3B: Combine/compare process stories and BPMN}

16. How do you think about the proposed method regarding its ability to integrate the abstract and concrete?

17. Which model can help you understand more regarding business process elements: activities or narrative elements?

18. (General versus specific):

a. Which model provide you an overall picture?

b. Which model provide you further details?

19. How would you use process stories in your business/role? 


\section{Appendix B: An Example of Process Stories and BPMN Model}

\section{Process Stories of Lottery distribution}

\section{Introduction}

Hung is a manager of a tier 1 wholesaler in the traditional lottery industry for 4 years so he knows the process from ticket collection to distribution. In this industry in the South Vietnam, there is one lottery company in each province and their lottery calendar happens once a week, except Ho Chi Minh city. Although there are 21 companies corresponding to 21 provinces, the wholesaler only works directly with 3 of them (specifically Dong Thap, Ho Chi Minh and Dong Nai) but in large quantity in order to trade them for tickets of other companies from other wholesalers.

Why choose this industry:

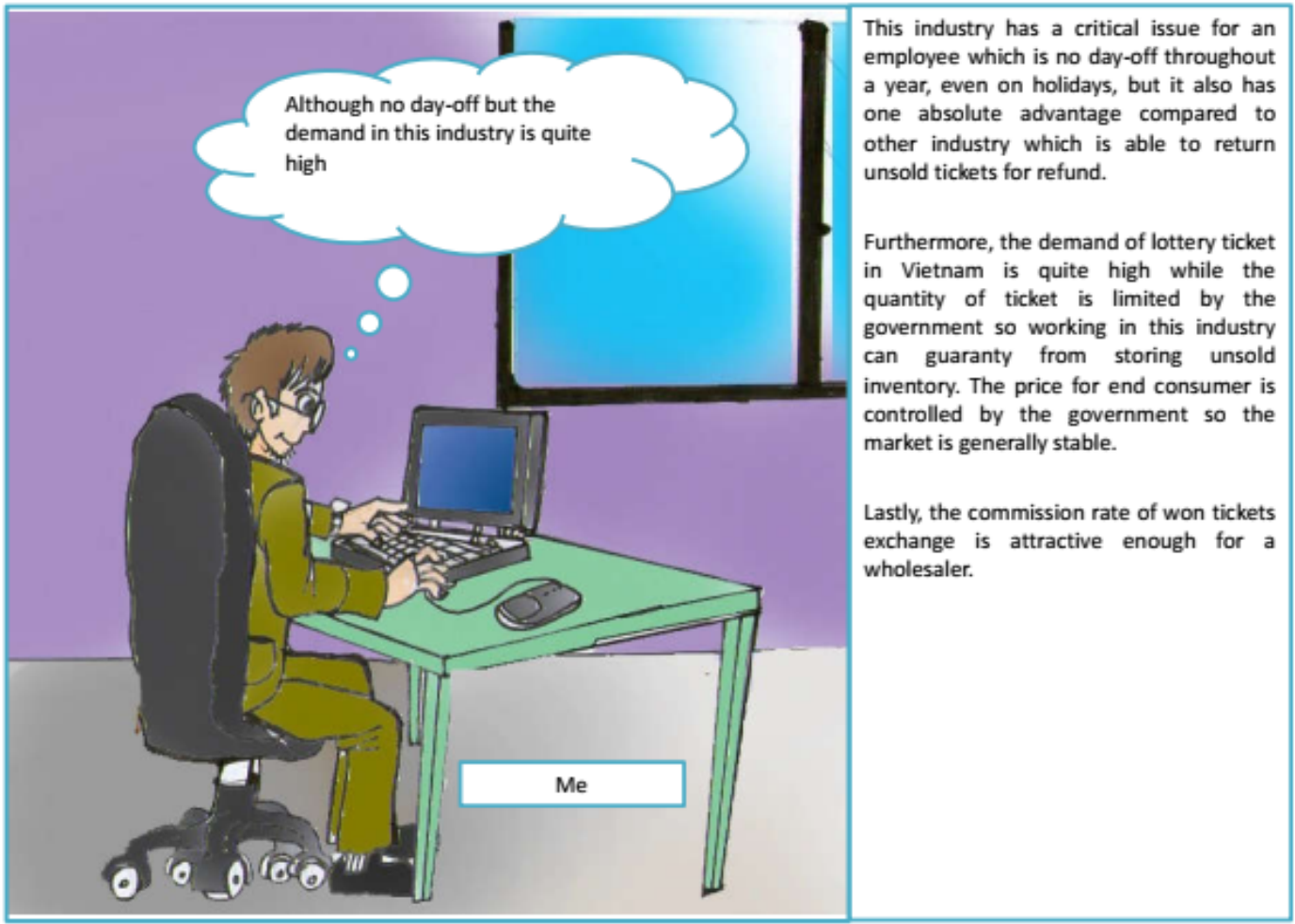


New ticket payment for company:

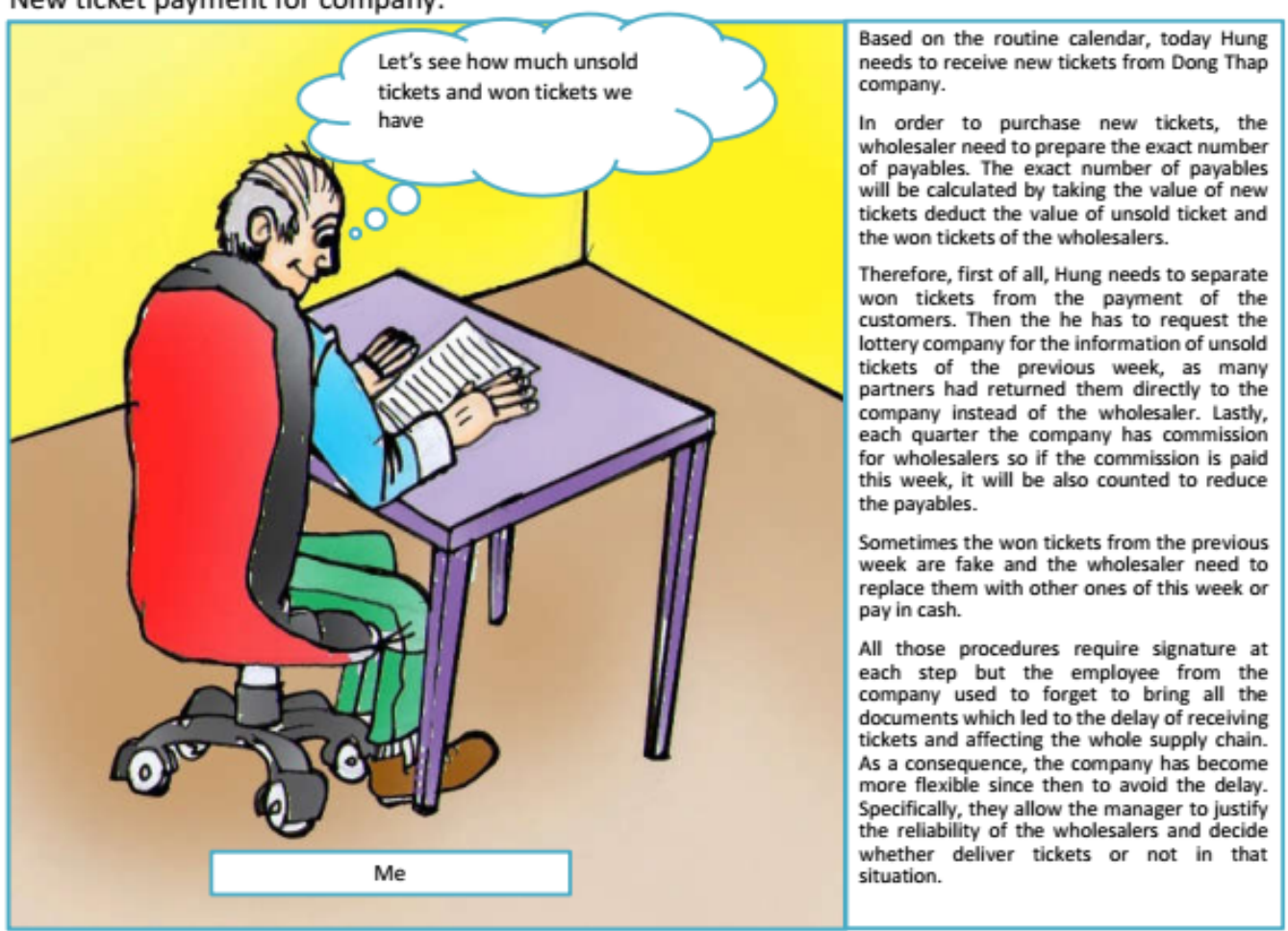

Ticket received and delivered

to warehouse:

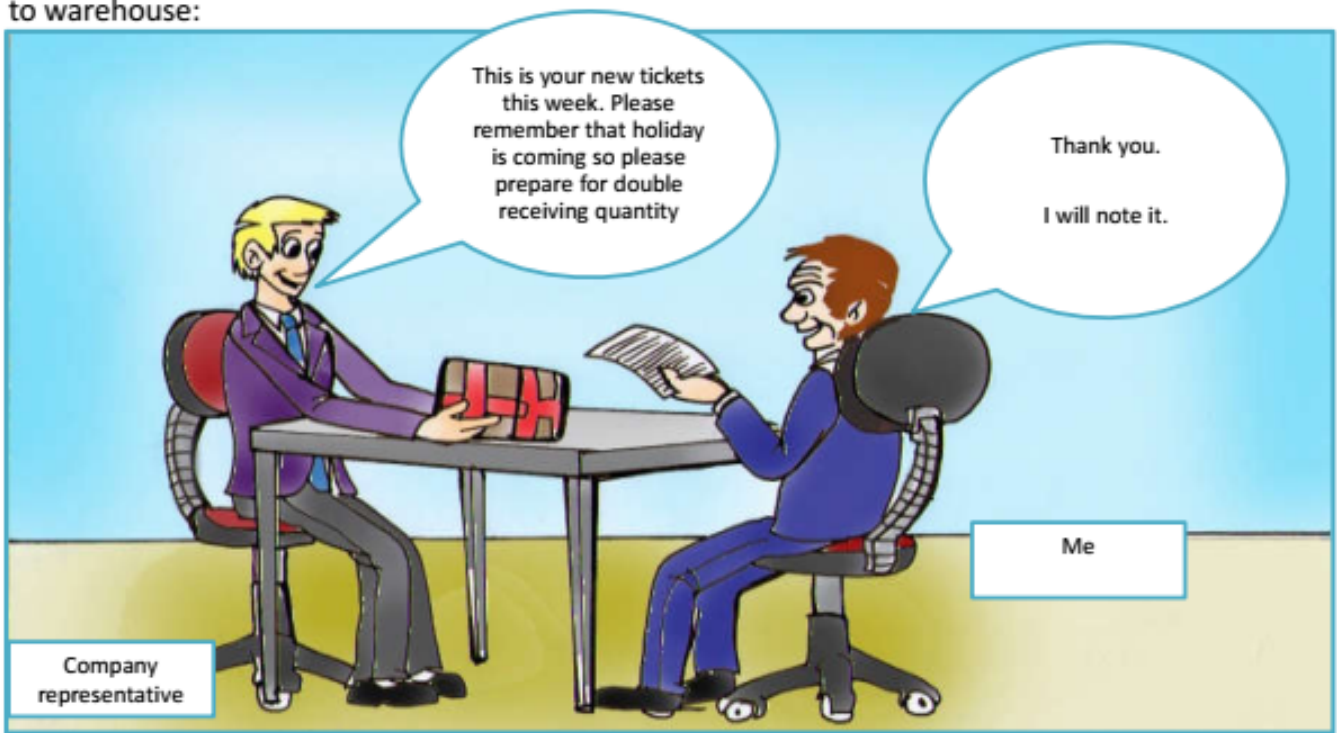

The tickets will be then delivered to the wholesaler's warehouse by private vehicles like cars or motorbikes.

In one case, in the Tet holiday, although wholesaler cannot have day-off but the companies have them in common, so the representative office is closed at that time. Thus, the company has to deliver the tickets of two weeks at the same time in one week prior to Tet holiday, and it caused double quantity to store in the representative office. One time due to inventory

overload, the tickets were transported directly to wholesaler's warehouse by the company's vehicle. 
Distribution/trade plan for tier

1 agents:

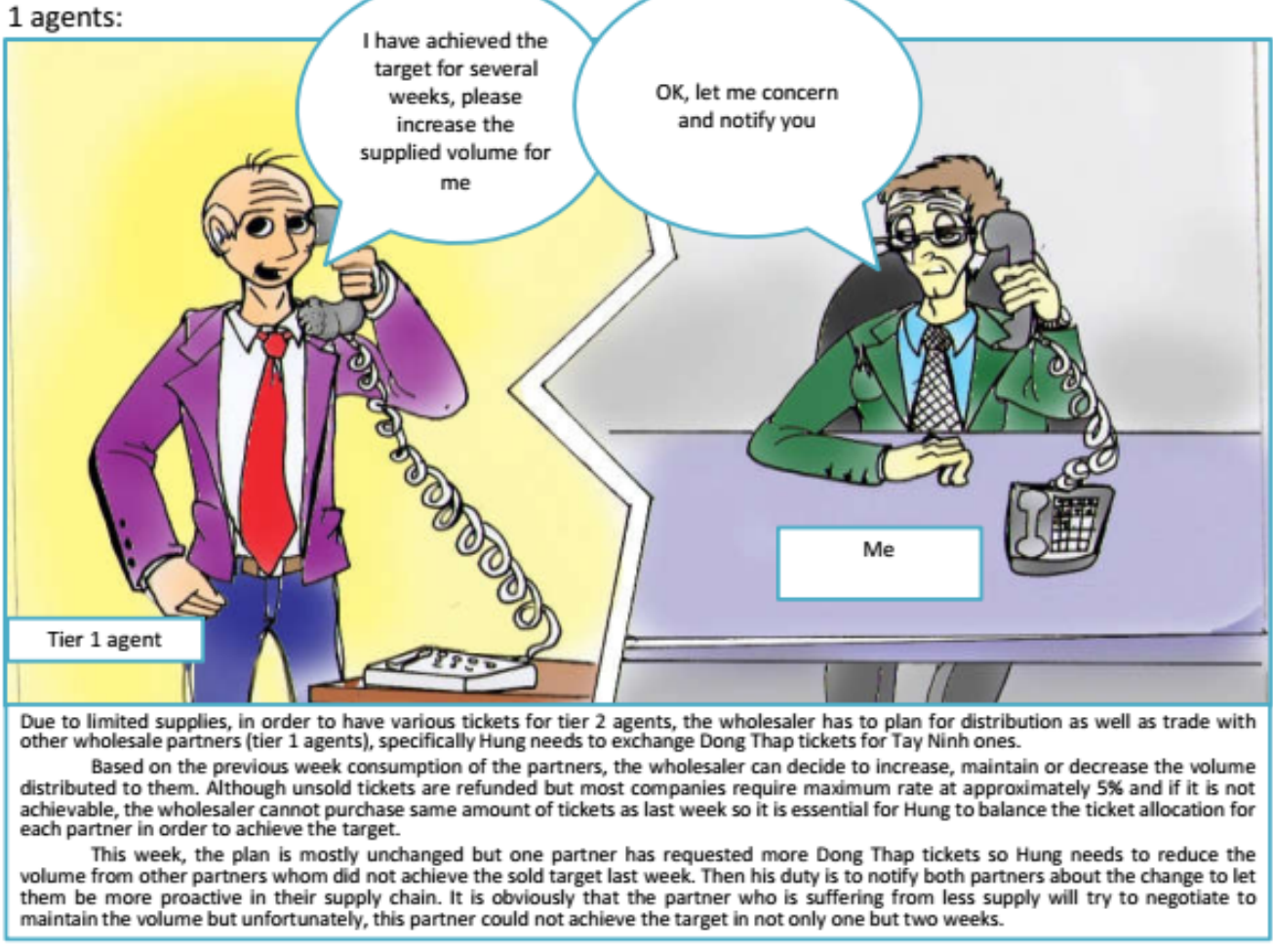

Distribution/ trade with tier 1

agents

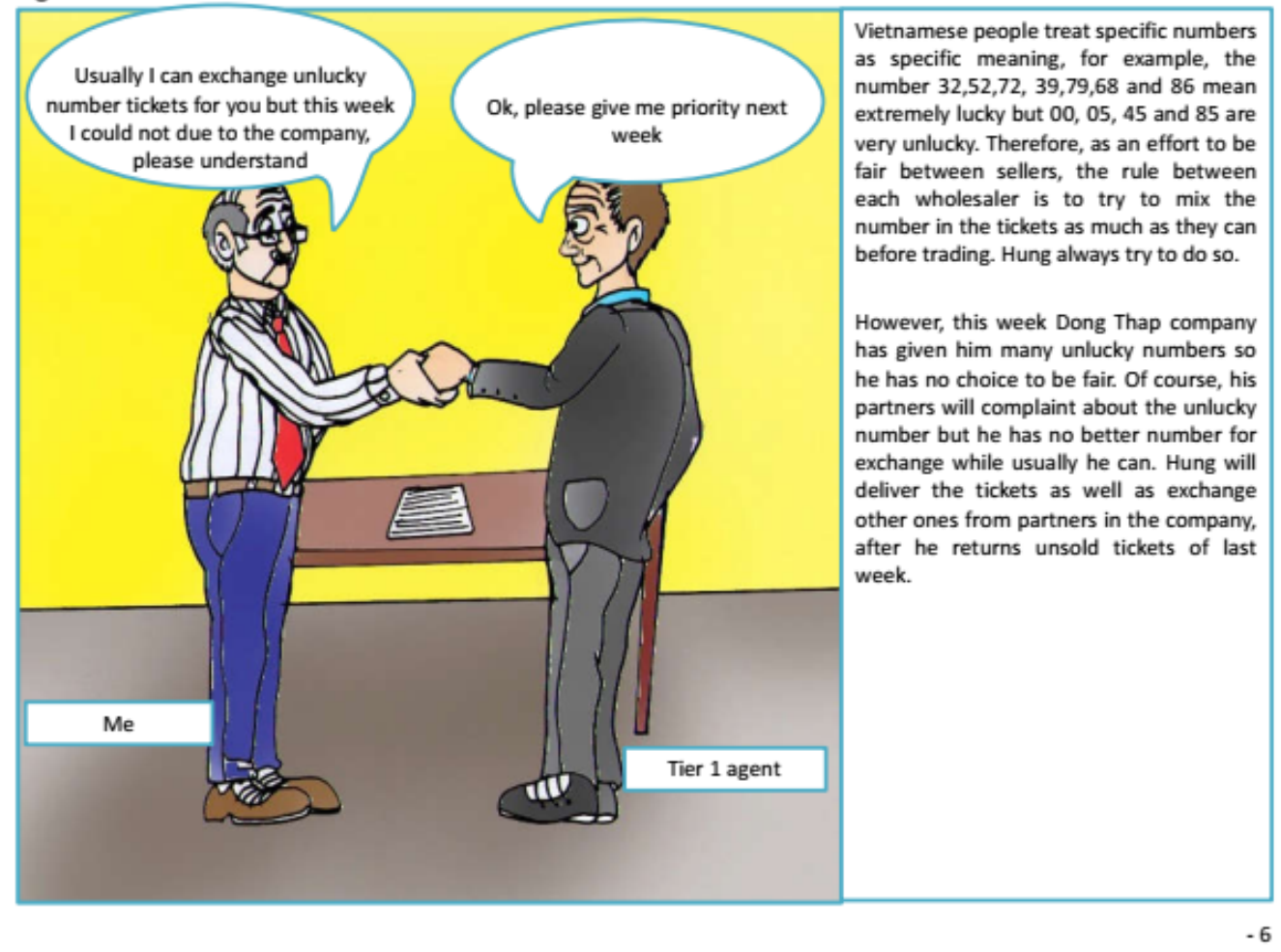


Payment from tier 1 agents

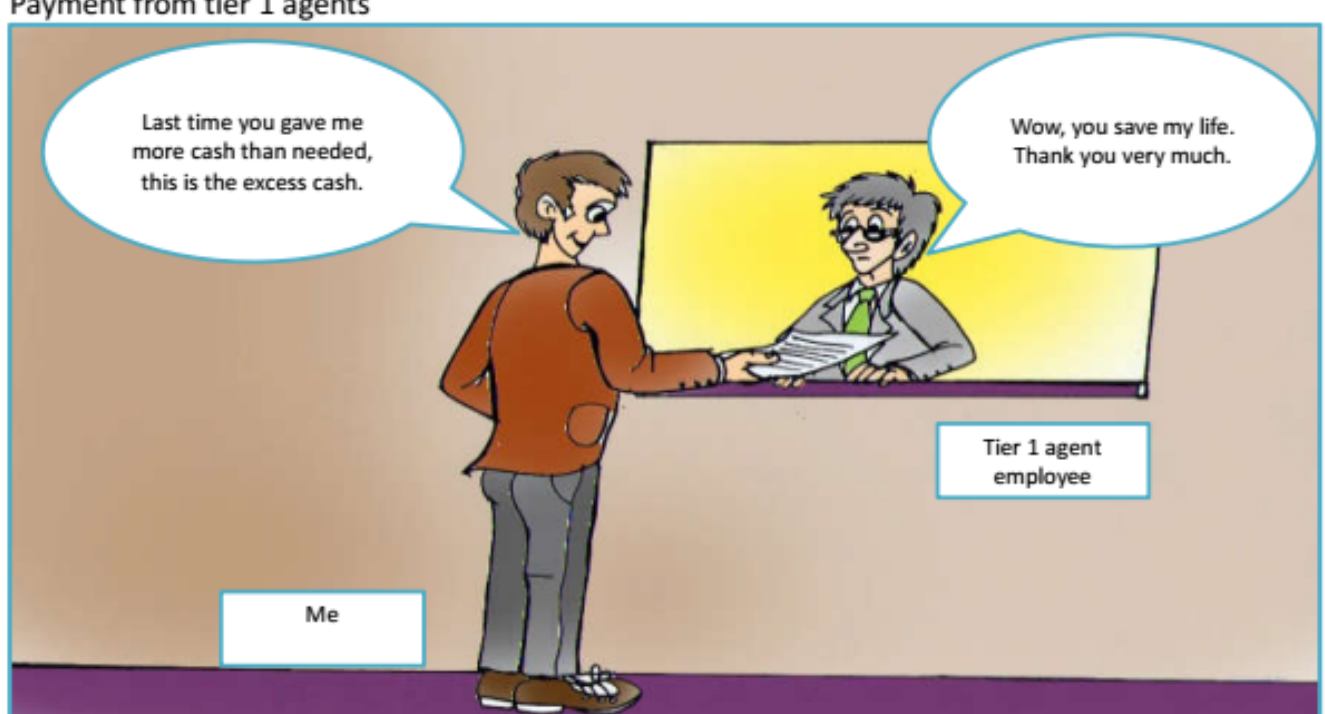

Hung need to pay partners if he requests tickets from them more than they request and the payment methods can be cash, bank and won tickets. The payment process also happens in the company, after returning unsold tickets.

This week, as one company request more Dong Thap tickets so Hung has to adjust the account receivables from this partner as well as the partner that he has reduced the volume.

As the payment process happen quickly in the company so most representative of each wholesaler does not tally at that time but do it later. One time, one partner has given excess cash and Hung was happy to return back to them later to avoid their employee being fired.

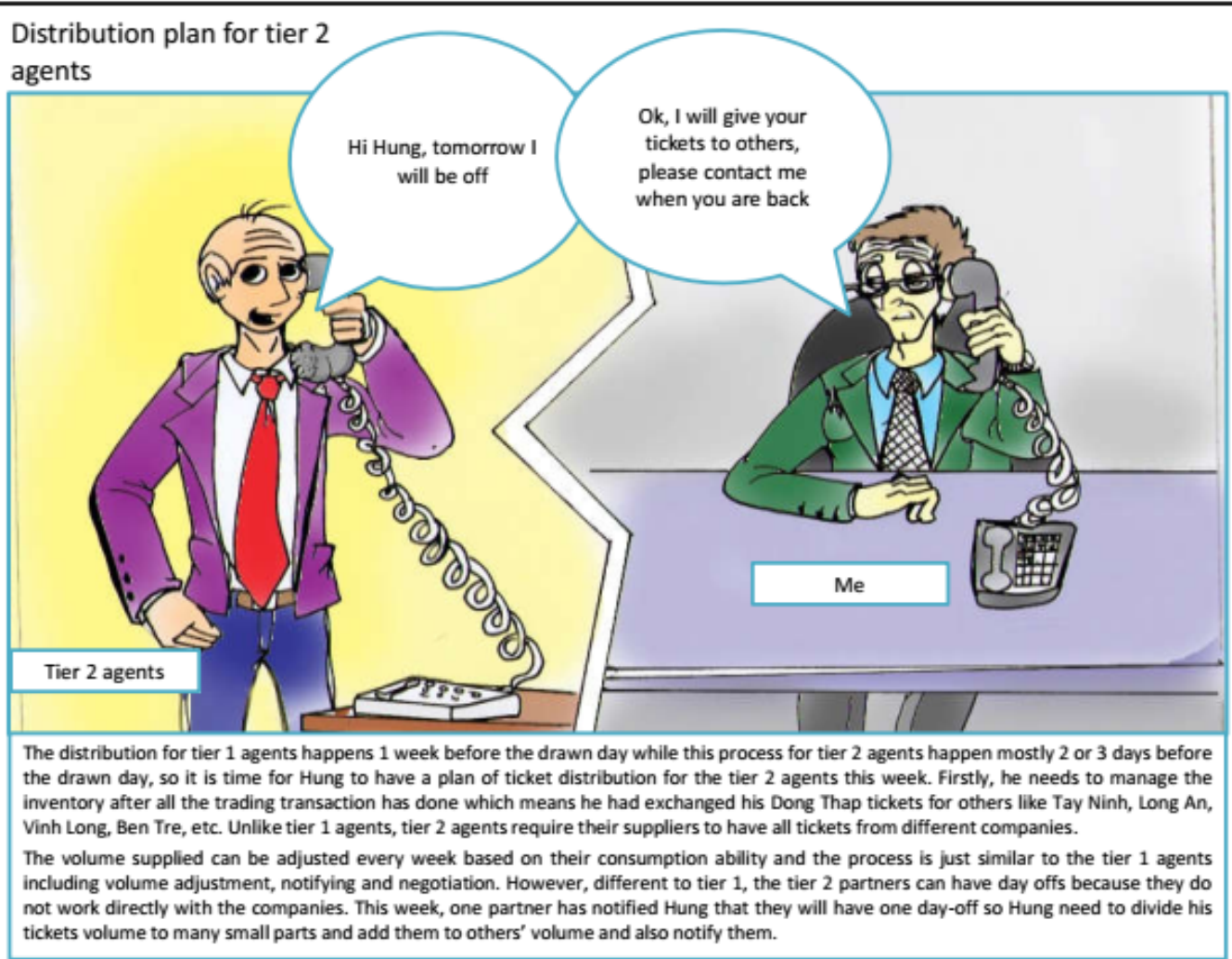




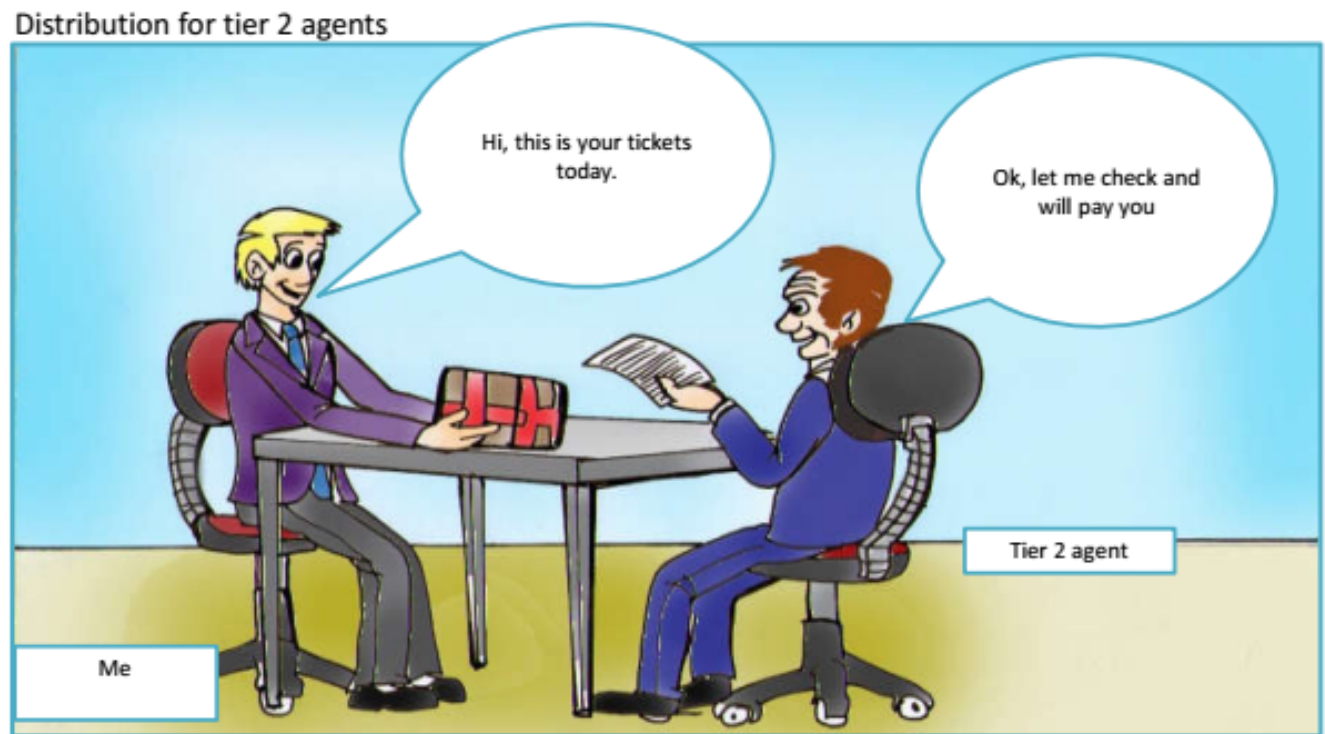

The tier 2 agents require even more numbers of tickets than the tier 1 but in smaller quantity so Hung has to mix tickets again at a smaller level and then deliver to them at their home or they will come and collect them at the wholesaler's warehouse.

\section{Payment from tier 2 agents}

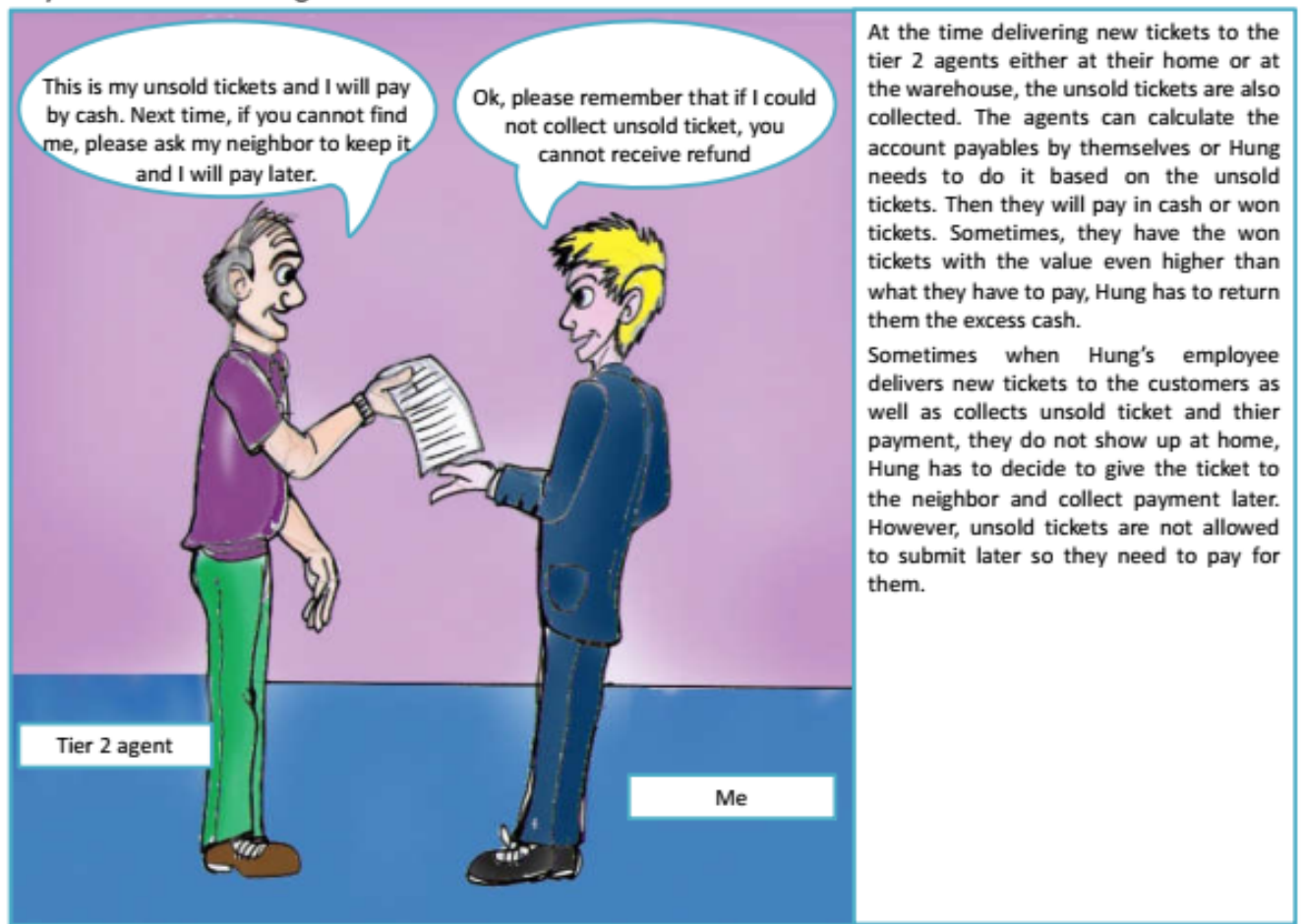


Return unsold ticket to

company

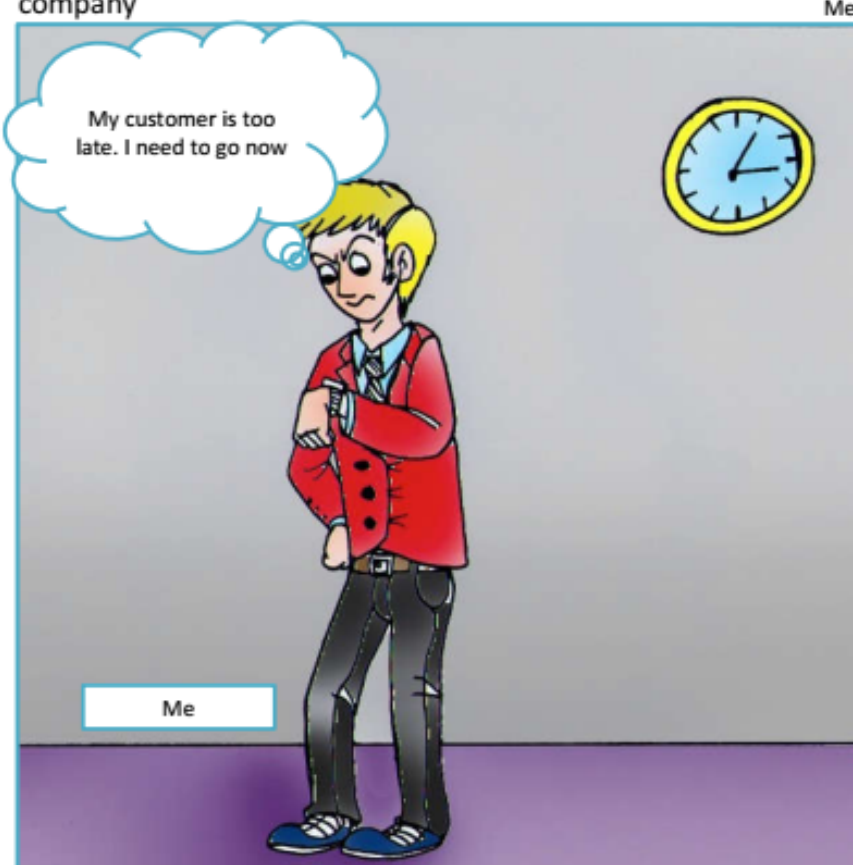

After collecting all the unsold tickets from the tier 2 agents, Hung has to deliver them to the company before $4 \mathrm{pm}$.

One time, the agent shown up too late that Hung had already been on his way to the company, then the agent had to go to the company by themselves and also contacted Hung as soon as possible to adjust the sheet of total unsold ticket volume.

Another time, due to being too late, the company did not accept the unsold tickets so the agents could not receive a refund.

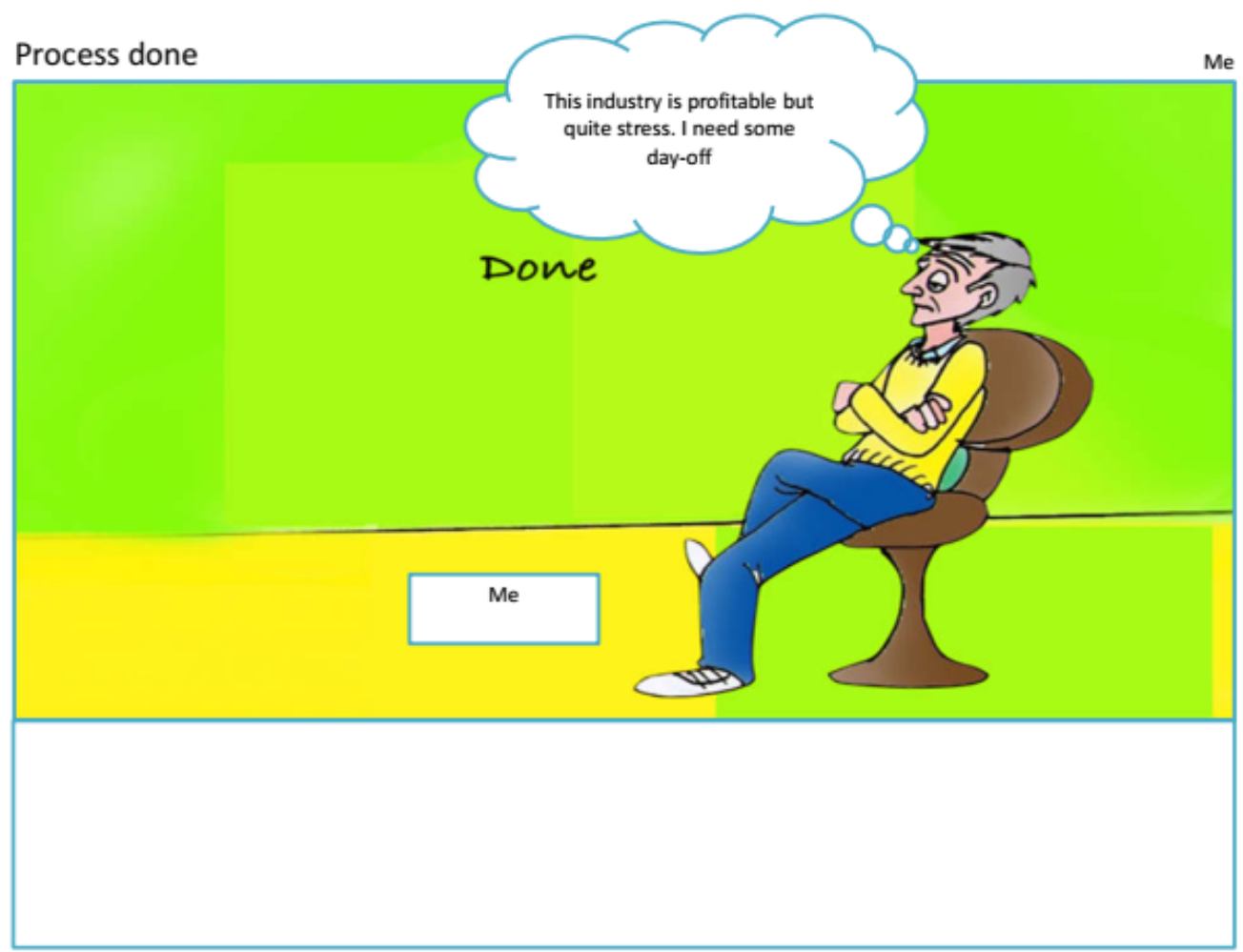


BPMN Models of Lottery distribution in a tier 1 wholesaler company in Vietnam
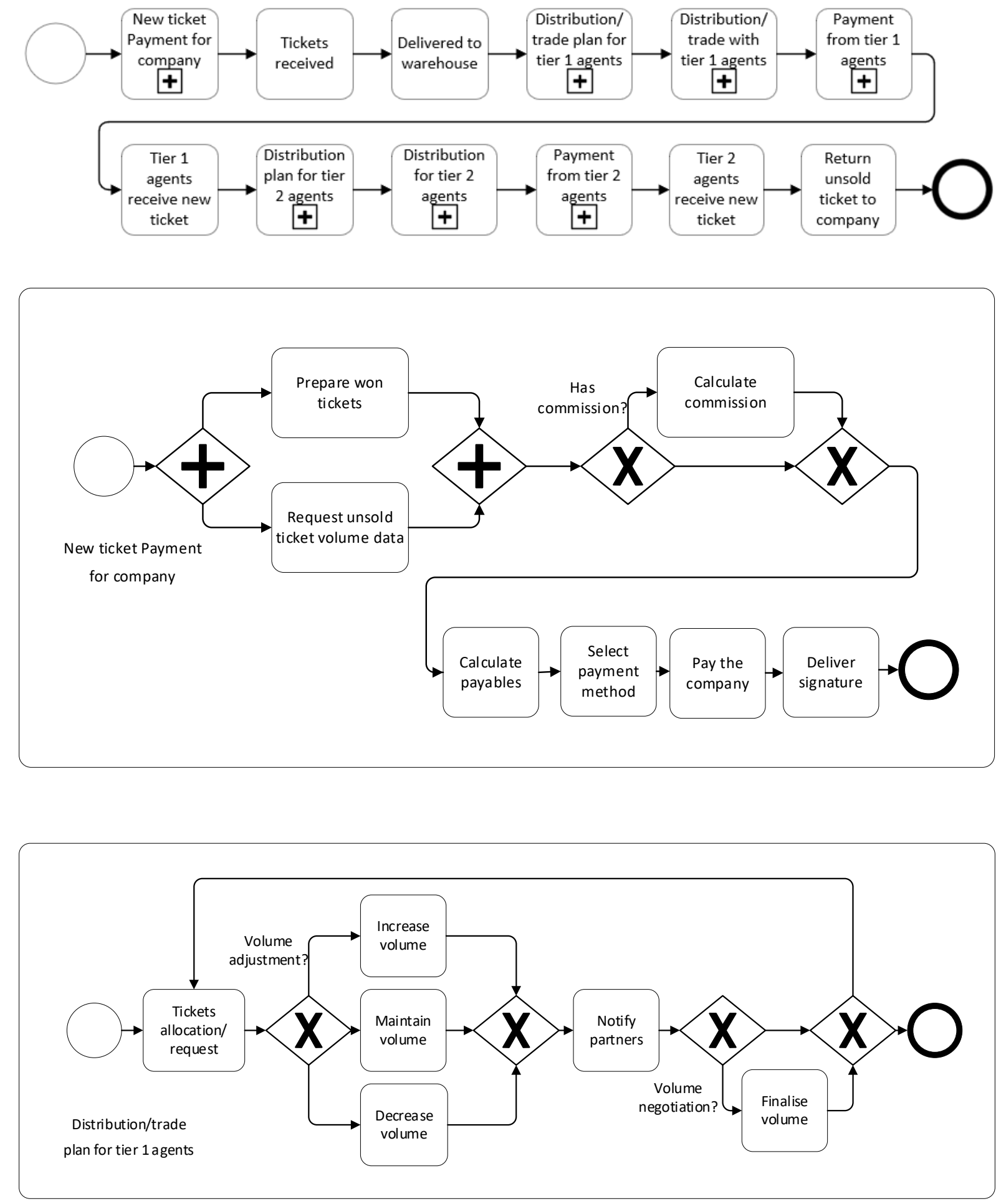

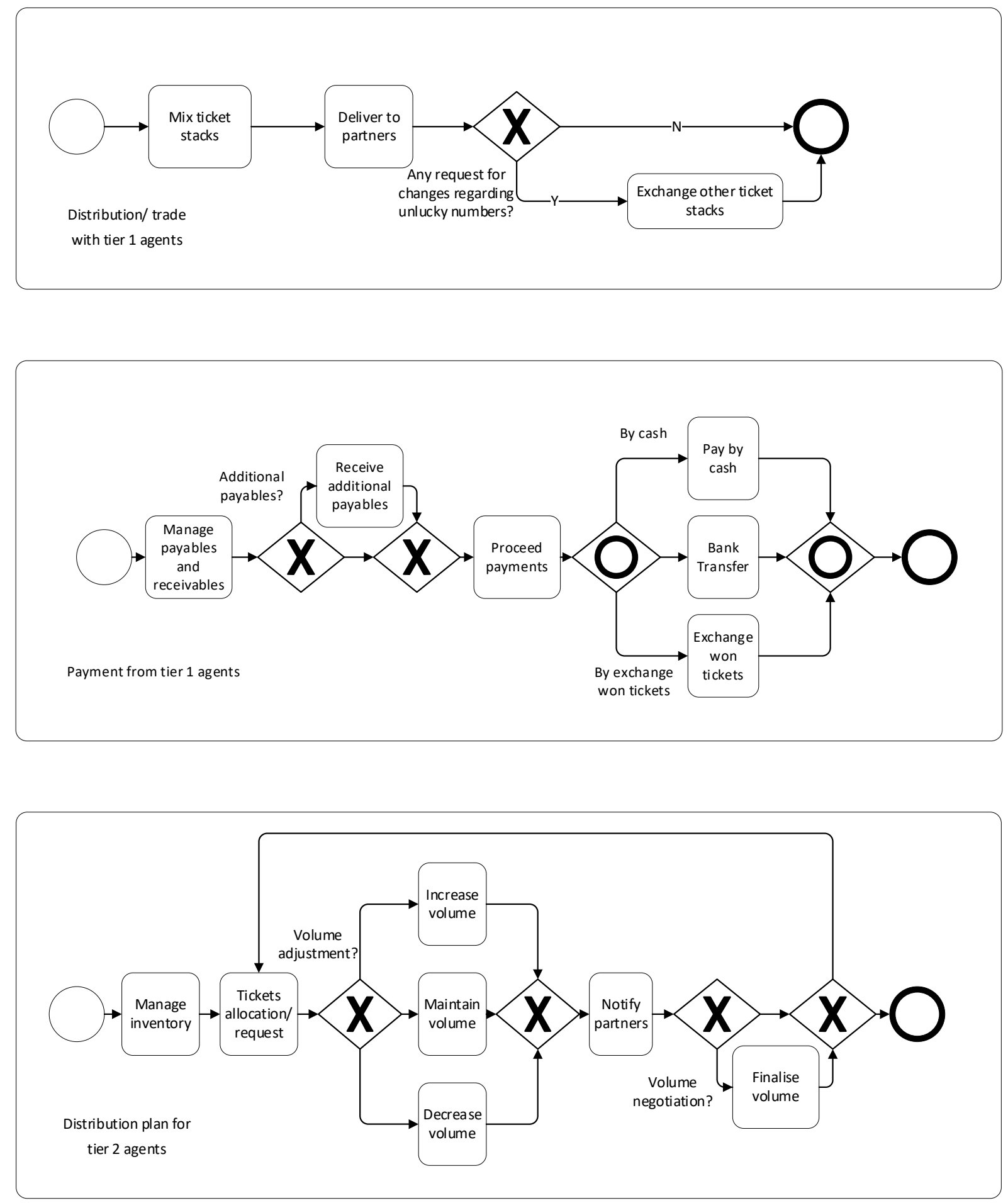

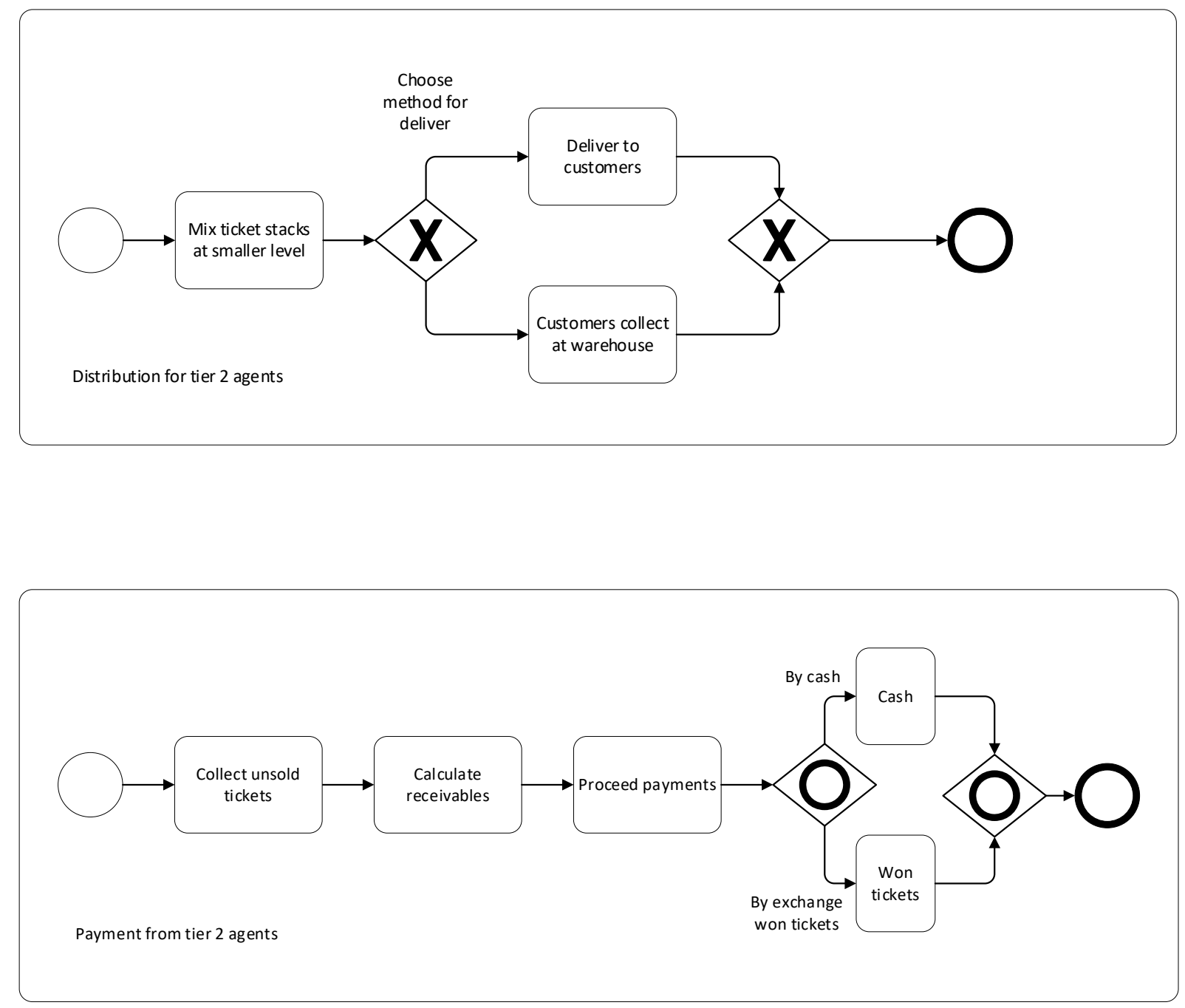

Copyright: () 2022 authors. This is an open-access article distributed under the terms of the Creative Commons Attribution-NonCommercial 3.0 Australia License, which permits noncommercial use, distribution, and reproduction in any medium, provided the original author and AJIS are credited.

doi: https://doi.org/10.3127/ajis.v26i0.3479

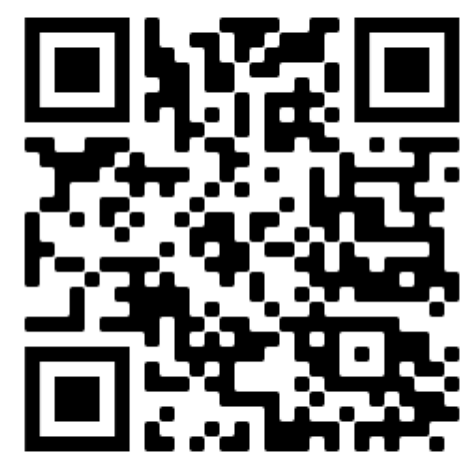

